$$
\begin{aligned}
& \text { Aus der Klinik Hals-Nasen-Ohrenheilkunde } \\
& \text { (kommisar. Direktor Prof. Dr. Martin Canis) }
\end{aligned}
$$

im Zentrum Augenheilkunde und Hals-Nasen-Ohrenheilkunde der Medizinischen Fakultät der Universität Göttingen

\title{
Funktionelle und onkologische Resultate der transoralen Laserchirurgie beim Zungengrundtumor
}

\author{
INAUGURAL-DISSERTATION \\ zur Erlangung des Doktorgrades \\ der Medizinischen Fakultät der \\ Georg-August-Universität zu Göttingen
}

vorgelegt von

Mei Iskandar

aus

Bad Berleburg 
Dekan:

Prof. Dr. rer. nat. H. K. Kroemer

I. Berichterstatter: Prof. Dr. M. Canis

II. Berichterstatter/in: PD Dr. H. Wolff

III. Berichterstatter/in: Prof. Dr. T. Meyer

Tag der mündlichen Prüfung: 10.12.2015 


\section{Inhaltsverzeichnis}

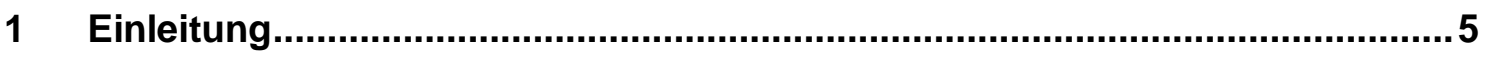

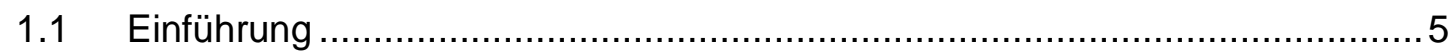

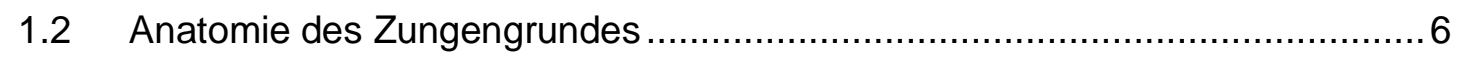

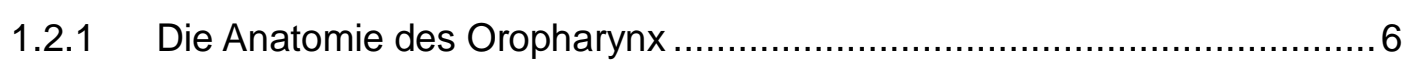

1.2.2 Aufbau der Zunge ................................................................... 7

1.3 Risikofaktoren für die Entstehung eines Zungengrundkarzinoms.......... 7

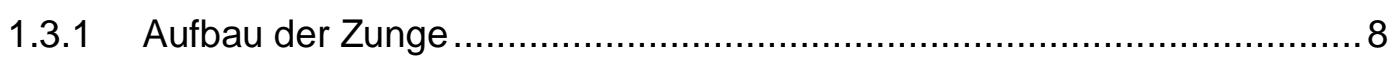

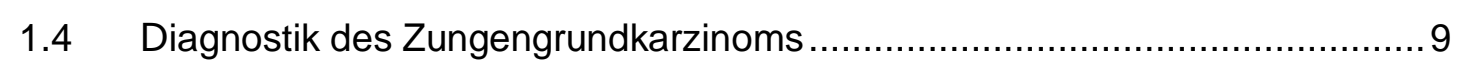

1.5 TNM-Klassifikation und Tumorstadien.................................................. 10

1.6 Grundlagen therapeutischer Möglichkeiten .............................................. 13

1.6.1 Operative Therapie in frühen Stadien des Zungengrundkarzinoms ......... 14

1.6.2 Primäre Radiotherapie in frühen Stadien ......................................... 14

1.6.3 Operative Therapie in fortgeschrittene Stadien .................................. 15

1.6.4 Primäre Radio(chemo)therapie in fortgeschrittenen Stadien ................... 15

1.6.5 Adjuvante Radio(chemo)therapie.................................................. 16

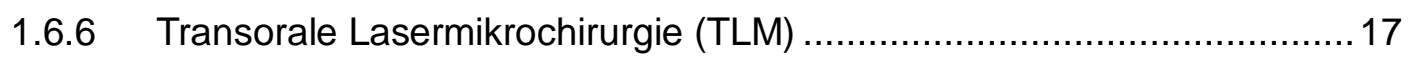

1.6.7 Vorteile der laserchirurgischen Resektion .......................................... 18

1.7 Prognose nach kurativer Therapie ..................................................... 20

1.8 Therapie der regionären Lymphabflussgebiete beim Zungengrundkarzinom 20

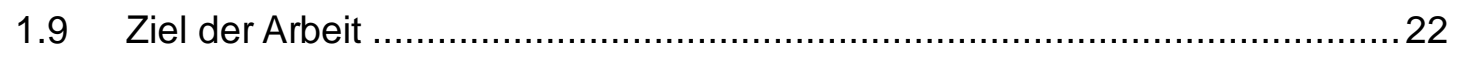

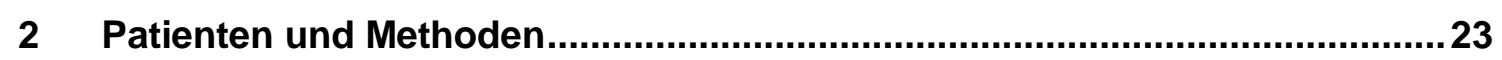

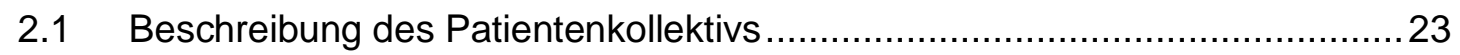

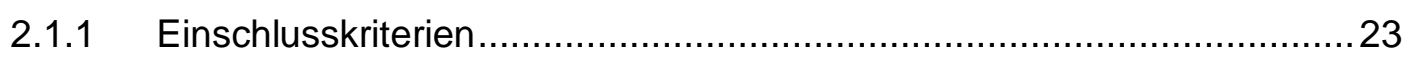

2.1.2 Ausschlusskriterien ................................................................. 23

2.1.3 Alter- und Geschlechtsverteilung ............................................... 24

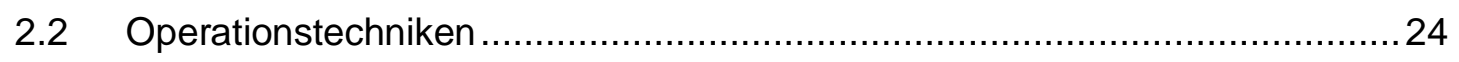

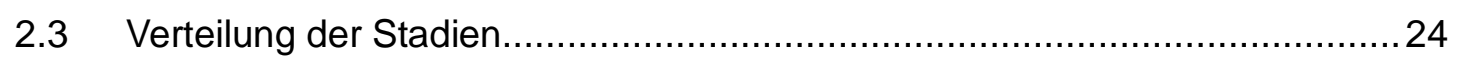

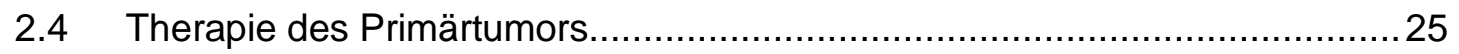

2.5 Präoperative Diagnostik und Therapie der Halslymphknoten ........................25

2.6 Adjuvante Radio(chemo)therapie.......................................................26

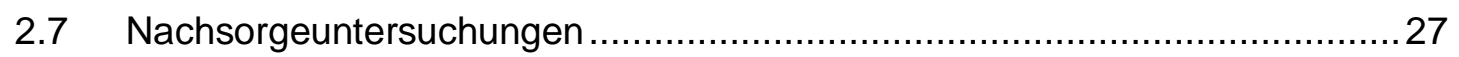

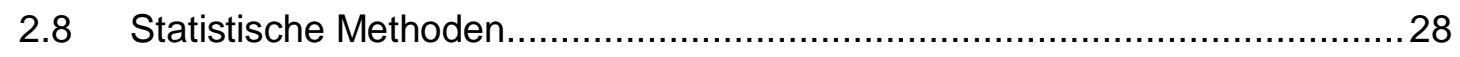

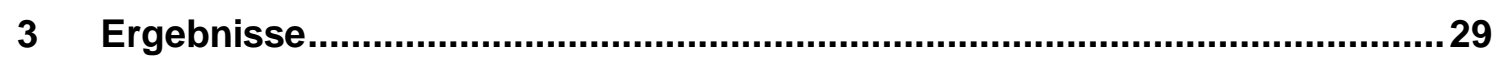

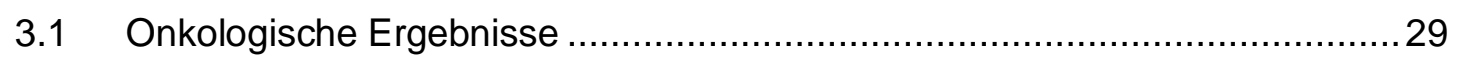

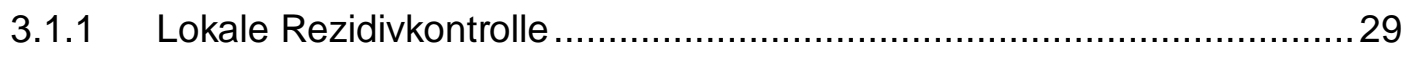

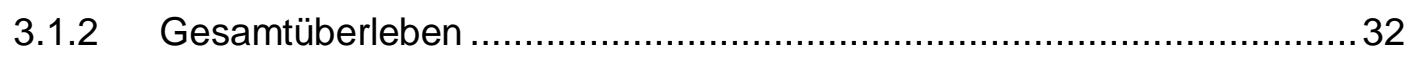




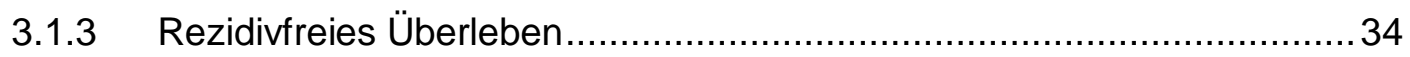

3.2 Häufigkeit und Lokalisation von Zweittumoren ..........................................38

3.3 Komplikationen und funktionelle Ergebnisse ............................................38

4 Diskussion ................................................................................................ 40

4.1 Bewertung der onkologischen Ergebnisse in der Literatur ..........................40

4.1.1 Gesamtüberleben nach offener Chirurgie alleine oder mit adjuvanter

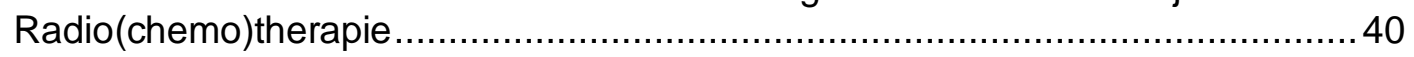

4.1.2 Lokale Kontrolle nach Kombinationstherapie ……….......................... 43

4.1.3 onkologische Ergebnisse nach primärer Strahlentherapie .....................44

4.1.4 lokale Kontrolle nach Laserchirurgie mit oder ohne adjuvante

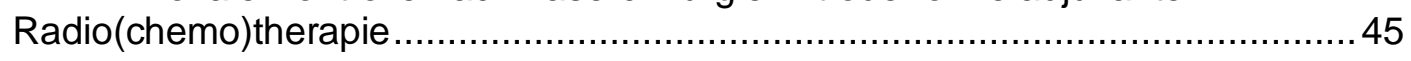

4.1.5 Gesamtüberleben nach Laserchirurgie alleine oder mit adjuvanter

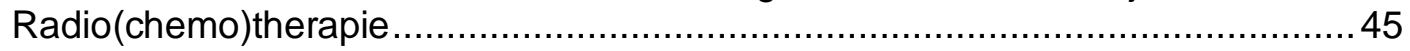

4.2 Fernmetastasen nach primärer Chirurgie................................................. 47

4.3 Bewertung der funktionellen Ergebnisse in der Literatur .............................. 48

4.3.1 Funktionelle Ergebnisse im Vergleich von konventioneller Chirurgie und primärer Radio(chemo)therapie..................................................................... 48

4.3.2 Funktionelle Ergebnisse nach transoraler Laserchirurgie....................... 49

4.4 Bewertung der Komplikationen in der Literatur..........................................50

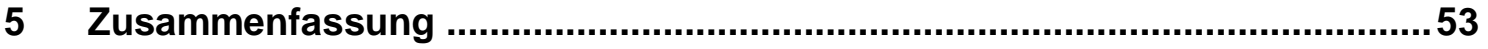

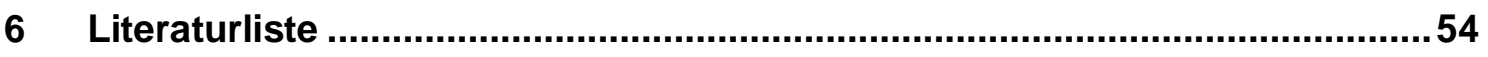

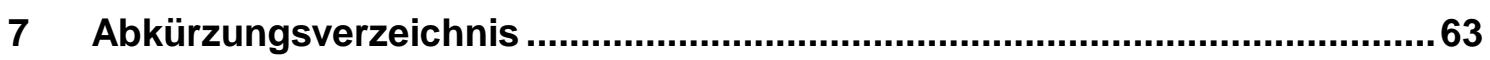




\section{Einleitung}

\subsection{Einführung}

Die geschätzte jährliche Prävalenzrate von Kopf- und Hals-Tumoren liegt in der Bundesrepublik, in anderen westeuropäische Ländern sowie in den USA bei etwa 15 pro 100.000 Einwohner (Wittekindt et al. 2012). Kopf-Hals-Tumoren machen somit etwa $5 \%$ aller bösartigen Karzinome aus (Wittekindt et al. 2012). Während die Anzahl der Neuerkrankungen an Kopf-Hals-Tumoren in der Gesamtheit sinkt, was vor allem auf den Rückgang der Zahl der Raucher zurückgeführt werden kann, zeigen Tonsillen- und Zungengrundkarzinome in verschiedenen Studien steigende Inzidenzraten (Wittekindt et al. 2012, Sturgis und Cinciripini 2007). Ein bedeutender Grund dafür ist die zunehmende Anzahl an Human-Papillomavirus-assoziierten (HPV) Tumoren (Chaturvedi et al. 2011).

Trotz aller diagnostischer und therapeutischer Fortschritte zeigt sich die durchschnittliche Fünf-Jahres-Überlebensrate während der letzten 40 Jahre bei den KopfHals-Tumoren fast unverändert (Wittekindt et al. 2012). Dies liegt insbesondere bei den Zungengrundkarzinomen daran, dass in $80 \%$ der Fälle bei Tumordiagnose bereits lokal fortgeschrittene Karzinome der Stadien III und IV vorlagen. Darüber hinaus ist eine Früherkennung meist nicht möglich, weil Symptome erst spät auftreten (Camp et al. 2009). Bei zwei Dritteln aller Patienten sind bei Diagnosestellung schon Lymphknotenmetastasen vorhanden (Steiner et al. 2003). Aus diesen Gründen haben Tumoren des Oropharynx eine schlechte Prognose (López-Álvarez et al. 2011). 


\subsection{Anatomie des Zungengrundes}

\subsubsection{Die Anatomie des Oropharynx}

Der Zungengrund gehört zur anatomischen Struktur des Oropharynx und bildet das hintere Drittel der Zunge. Kranial schließt sich der Nasopharynx, kaudal der Hypopharynx an. Von der Epiglottis bis zum Zungengrund verlaufen die mediale und laterale Plica glossoepiglottica und begrenzen die Valleculae. Ausgekleidet ist der Zungengrund von mehrschichtigem Plattenepithel. Dieses stellt den Ursprung der meisten malignen Tumoren dar, so dass das Plattenepithelkarzinom die häufigste Tumorhistologie ist (Sigal et al. 1996).

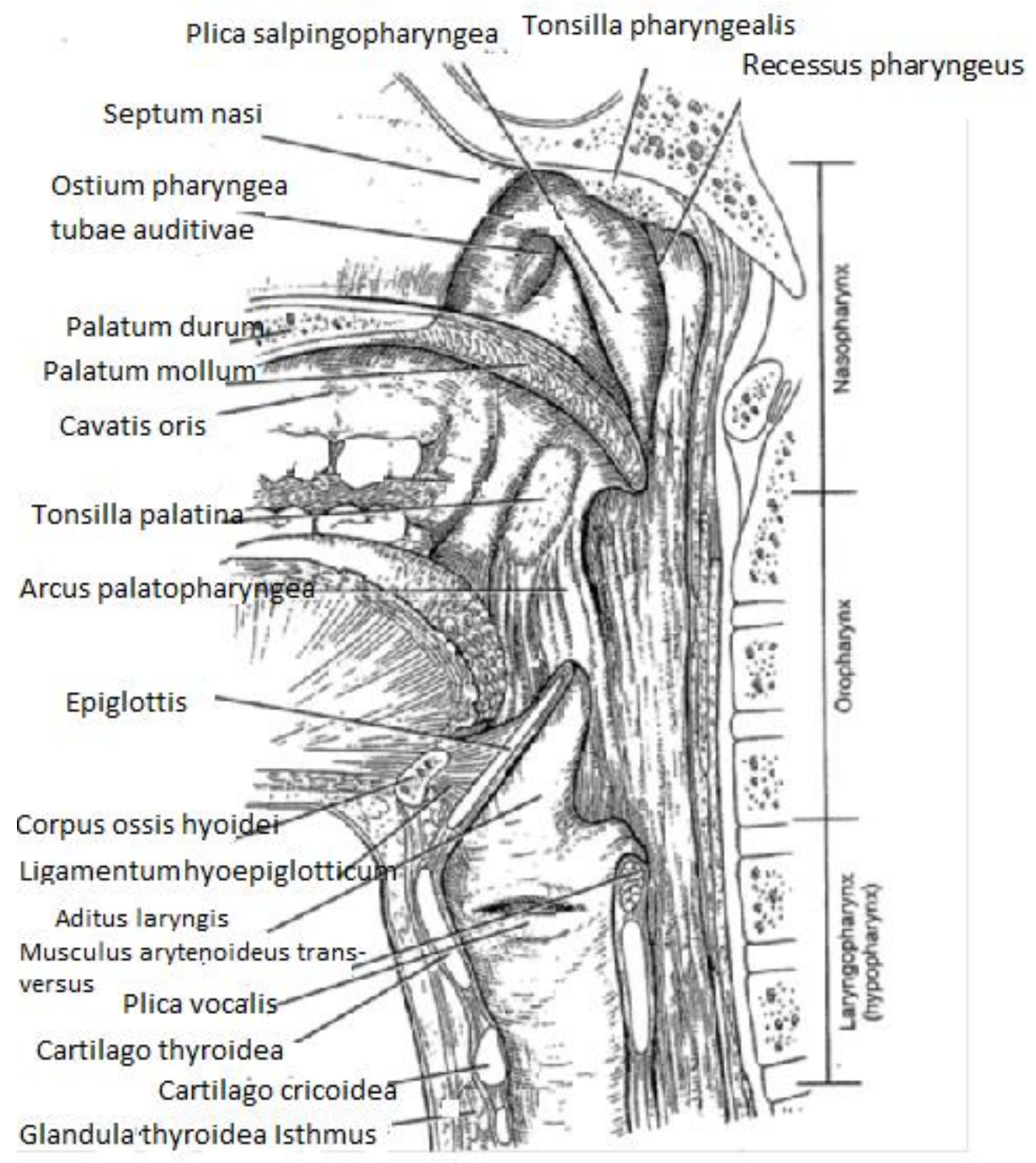

Abbildung 1: Anatomie des Oropharynx (Duvvuri und Meyers 2009, Seite 120) 


\subsubsection{Aufbau der Zunge}

Die Teilung der Zunge in einen anterioren mobilen Teil und den Zungengrund erfolgt durch die Papillae vallatae. Diese bestehen aus acht bis zwölf Erhebungen, die die Form eines umgekehrten $V$ bilden. Die Schleimhaut ist von lymphatischem Gewebe bedeckt, welches die Tonsilla lingualis formt (Sigal et al. 1996).

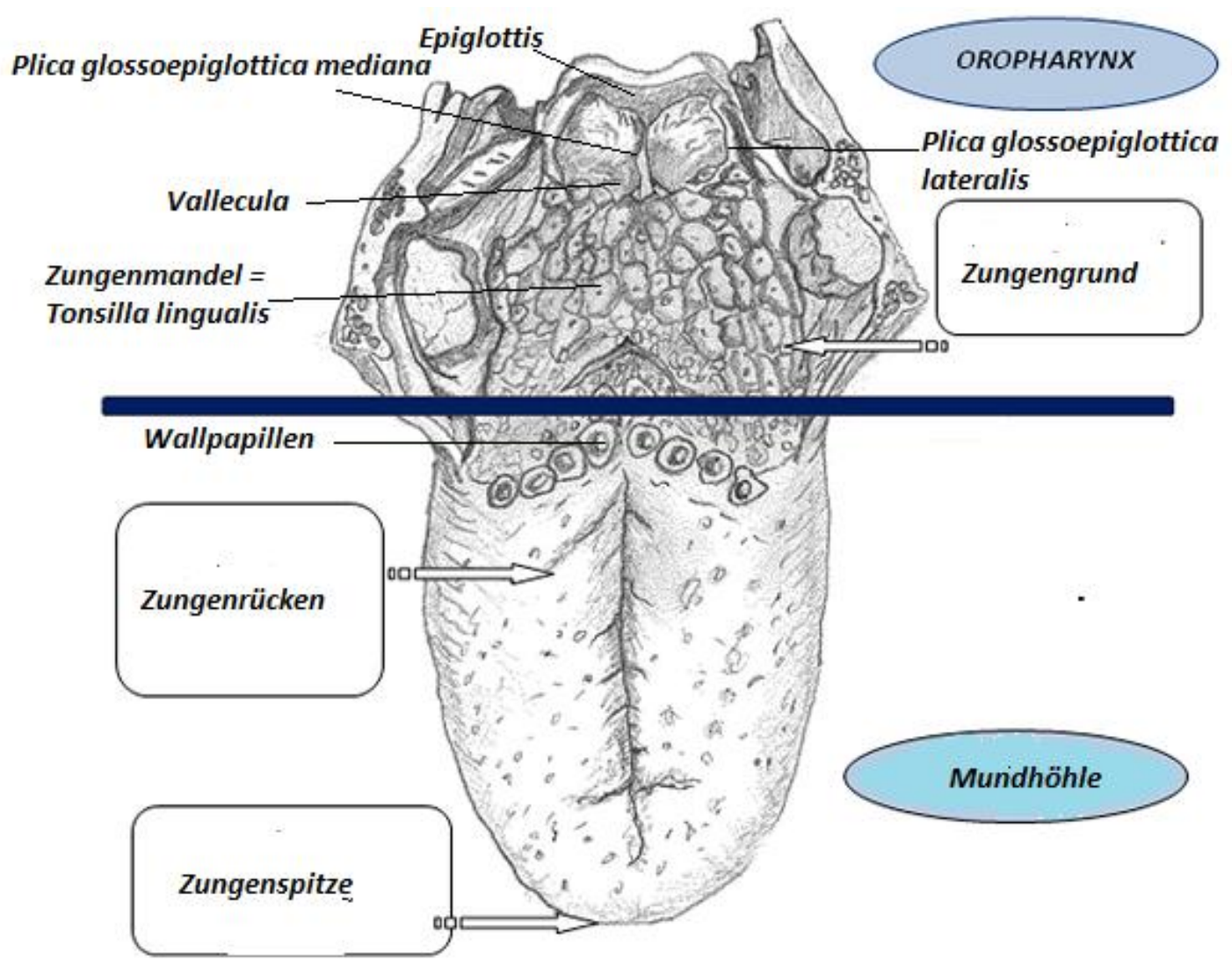

Abbildung 2: Aufbau der Zunge (Croce et al. 2012, Seite 5)

\subsection{Risikofaktoren für die Entstehung eines Zungengrundkarzinoms}

Die Entstehung des Zungengrundkarzinoms und von Kopf-und-Hals-Tumoren ist von vielen Einflüssen abhängig. Die klassischen Risikofaktoren sind der Alkoholund Tabakkonsum. Rauchen mit gleichzeitigem Alkoholabusus bewirkt einen synergistischen Effekt (Wittekindt et al. 2012). Alkoholkonsum verstärkt die genotoxischen Effekte von Karzinogenen im Tabakrauch (Nitrosamine, polyzyklische Kohlenwasserstoffe). Weitere Risikofaktoren sind eine positive Familienanamnese, 
inhalative Noxen (Holz- und Metallstäube, Chrom sowie nickelhaltige Farben und Lacke), kanzerogene Chemikalien (polyzyklische aromatische Kohlenwasserstoffe), UV- und radioaktive Strahlung, Virusinfektionen (HPV, HIV, EBV), mangelnde Mundhygiene und ein geschwächtes Immunsystem (Wittekindt et al. 2012).

\subsubsection{HPV-assoziierte Karzinome}

Seit ungefähr zwei Jahrzenten gilt das humane Papillomavirus (HPV) neben den „klassischen“ Risikofaktoren Alkohol- und Nikotinabusus als ein zusätzlicher Risikofaktor für das Zungengrundkarzinom (Lassen et al. 2009, D'Souza et al. 2007). Die Zunahme an Zungengrundkarzinomen ist auf eine Infektion mit diesen Viren zurückzuführen (Wittekindt et al. 2012, D'Souza et al. 2007, Sturgis und Cinciripini 2007). Die Karzinogenese beruht auf einer Dysregulation des Zellzyklus. Die viralen Proteine E6 und E7 inaktivieren die Apoptose auslösenden Tumorsuppressorgene p53 (Tumor Protein) und Rb (Retinoblastom-Protein) der Wirtszellen (Wittekindt et al. 2012). Promiskuität sowie häufiger oraler Geschlechtsverkehr scheinen die Entstehung für die Entwicklung eines HPV-assoziierten Tumors zu begünstigen (Wittekindt et al. 2012). Dabei werden die Hochrisiko-HPV-Typen 16 und 18 als hauptsächlich ursächlich für die Entstehung eines Anteils der Kopf-Hals-Karzinome gesehen (Goon et al. 2009).

Die Häufigkeit der HPV-positiven Kopf-Hals-Karzinome ist je nach geographischer Region und Studie sehr unterschiedlich (Lajer und Buchwald 2010). In Deutschland sind etwa $30 \%$ bis $40 \%$ der Plattenepithelkarzinome im HNO-Bereich mit onkogenen Papillomaviren assoziiert (Wittekindt et al. 2012).

In einer US-amerikanischen Arbeitsgruppe von Gillison et al. (2000) wurde bei 62 der 253 untersuchten Patienten (das entspricht 25\%) mit Kopf-Hals-Tumoren HPVDNA (Desoxyribonukleinsäure) im Tumorgewebe mittels In-situ-Hybridisierung und Polymerase-Kettenreaktion (PCR) nachgewiesen. HPV-positive Kopf-Hals-Karzinome zeigen eine bessere Prognose (Wittekindt et al. 2012). In der Mehrheit verschiedener Studien beträgt das Gesamtüberleben nach zwei Jahren für HPVpositive Tumoren $80 \%$ bis $85 \%$ und für HPV-negative $30 \%$ bis 35\%, offensichtlich unabhängig von der spezifischen Therapie (Wittekindt et al. 2012). Von besonderer Bedeutung für die bessere Prognose ist möglicherweise das HPV-assoziierte Onkoprotein E6. Ionisierende Strahlungen in der Therapie reduzieren die Fähigkeit von E6, die Tumorsuppressorproteine p53 sowie Rb zu inaktivieren, wodurch die DNA-Reparaturmechanismen erhalten bleiben, sich die Apopteseresistenz gegen- 
über der Strahlentherapie erniedrigt und sich die Empfindlichkeit auf die Therapie erhöht (Wittekindt et al. 2012). Da HPV-positive Tumoren meist regionär metastasiert sind, erfolgt häufig die Strahlentherapie und nicht die alleinige Operation (Wittekindt et al. 2012).

\subsection{Diagnostik des Zungengrundkarzinoms}

Zur Diagnostik gehört zunächst eine ausführliche Anamnese, in der unter anderem nach Beschwerden im Mundhöhlenbereich gefragt wird. Patienten können hierbei über Symptome wie Dysphagie, Heiserkeit, Gewichtsverlust und Ohrenschmerzen berichten. Vielfach bestehen Risikofaktoren wie Alkohol- und/oder Nikotinkonsum (Wittekindt et al. 2012). Nicht selten besteht eine schmerzlose Gewebezunahme im Bereich des Halses (Harrison et al. 2003). Häufig ist diese Gewebezunahme im Sinne von Halslymphknotenmetastasen das erste Symptom bei bereits fortgeschritteneren Tumoren, weil die Erkrankung lange Zeit asymptomatisch bleibt (Zhen et al. 2004). Eine ausführliche Hals-Nasen-Ohren-ärztliche Untersuchung folgt mit Inspektion von Mundhöhle und Pharynx und Palpation des Halses, bei der eine Raumforderung getastet bzw. gesehen werden kann (Harrison et al. 2003). Des Weiteren erfolgt eine Endoskopie von Pharynx und Larynx. Die präoperative Diagnostik beinhaltet auch eine Panendoskopie in Vollnarkose. Diese hat den Zweck, eine Größeneinschätzung des Tumors und somit dessen Operabilität festzulegen, eine histologische Sicherung mittels Biopsie durchzuführen und Zweittumoren auszuschließen (Bootz 2000).

Ferner erfolgt die Ultraschalldiagnostik der Halsweichteile. Die Sonographie ist ein Routineverfahren, um Raumforderungen des Halses und Prozesse in der Mundhöhle und Oropharynx zu detektieren (Iro und Waldfahrer 2009). Weitere bildgebenden Verfahren beinhalten neben einer Computertomographie (CT) des Halses und des Thorax eine präoperative Ultraschalluntersuchung des Abdomens um eventuelle Fernmetastasen darzustellen (Bootz 2000). Bei speziellen Fragestellungen stellt die Magnetresonanztomographie (MRT) eine ergänzende Untersuchung dar (Niederhagen et al. 2000). 


\subsection{TNM-Klassifikation und Tumorstadien}

Zur Tumorklassifikation werden die Einteilung des American Joint Committee on Cancer (AJCC) und das europäische Klassifikationssystem UICC

(Union Internationale Contre le Cancer) von Tumorstadien nach den TNMKategorien verwendet. Das TNM-Klassifikationssystem wurde von dem Franzosen Pierre Denoix in den Jahren 1943 bis 1952 ausgearbeitet. Es basiert auf statistischen Untersuchungen, die Aussagen über das voraussichtliche Verhalten der Tumorerkrankungen ab einer bestimmten Größe machen. Aktuell liegt vom UICC und AJCC jeweils die 7. Auflage vor. Die Änderungen, die in der 7. Auflage der TNM-Klassifikation bei den Kopf-Hals-Tumoren vorgenommen wurden, sind gering und betreffen im Wesentlichen die Oro- und Nasopharynxkarzinome. Neu formuliert wurde 2010 in der 7. Auflage der TNM-Klassifikation für die Kopf- und Hals-Tumoren die Definition der T3-Kategorie bei den Oropharynxkarzinomen als Tumor größer $4 \mathrm{~cm}$ in größter Ausdehnung oder Ausbreitung zur lingualen Oberfläche der Epiglottis. Als Anmerkung wurde hinzugefügt, dass diese Schleimhautausbreitung zur lingualen Oberfläche der Epiglottis von Primärtumoren des Zungengrundes und der Vallecula nicht als Invasion des Larynx gilt und somit nicht als T4a klassifiziert werden darf (Weber et al. 2010).

Das TNM-Schema berücksichtigt folgende Kategorien: Das T-Stadium klassifiziert Größe und Ausdehnung des Primärtumors,

die N-Kategorie regionäre Lymphknotenmetastasierung und das M-Stadium das Vorhandensein von Fernmetastasen. Das Grading gibt den Differenzierungsgrad an und erlaubt eine Aussage über den Malignitätsgrad des Tumors. Präoperativ wird vor der Stadienbezeichnung ein "c" hinzugefügt, welches angibt, dass es sich um die Klassifikation vor pathohistologischer Untersuchung handelt. Postoperativ wird vor der Stadienbezeichnung ein „p“ hinzugefügt, welches angibt, dass es sich um die Klassifikation nach pathohistologischer Untersuchung handelt (Wittekindt et al. 2012). 
Die folgenden Tabellen 1 bis 4 erklären die Bedeutung der TNM-Klassifikation nach den Leitlinien (Bootz 2000, Weber et al. 2010):

Tabelle 1: T-Klassifikation (Ausdehnung des Primärprozesses) des

Zungengrundtumors

Tx Primärtumor kann nicht beurteilt werden

T0 kein Anhalt für einen Primärtumor

Tis Carcinoma in situ

T1 Tumor $<2 \mathrm{~cm}$ in größter Ausdehnung

T2 Tumor $>2 \mathrm{~cm}$, jedoch $<4 \mathrm{~cm}$ in größter Ausdehnung

T3 $>4 \mathrm{~cm}$ in größter Ausdehnung oder Ausbreitung auf lingualer Fläche der Epiglottis

T4 Tumor infiltriert Nachbarstrukturen

T4a Tumor infiltriert Larynx, Zungenmuskulatur, harten Gaumen, Unterkiefer

T4b Tumor infiltriert M. pterygoideus lat., Schädelbasis, A. carotis int.

Tabelle 2: N-Klassifikation

\begin{tabular}{ll}
\hline N & Klassifikation \\
\hline Nx & regionäre Lymphknoten können nicht beurteilt werden \\
N0 & keine regionären Lymphknotenmetastasen \\
N1 & ipsilateraler solitärer Lymphknoten, maximal $3 \mathrm{~cm}$ \\
N2 & N2a: ipsilateraler solitärer Lymphknoten befallen, 3-6 cm \\
& N2b: ipsilaterale multiple Lymphknoten befallen, nicht \\
& größer als $6 \mathrm{~cm}$ \\
& N2c: Metastasen in bilateralen oder kontralateralen \\
& Lymphknoten, nicht größer als $6 \mathrm{~cm}$ \\
N3 & Lymphknotenmetastasen $>6 \mathrm{~cm}$ \\
\hline
\end{tabular}


Tabelle 3: Differenzierung und histopathologisches Grading

\begin{tabular}{ll}
\hline Grad & Differenzierung \\
\hline 1 & gut differenziert \\
2 & mäßig differenziert \\
3 & schlecht differenziert \\
4 & undifferenziert \\
5 & nicht bestimmbar \\
\hline
\end{tabular}

Tabelle 4: UICC-Stadien: Stadieneinteilung des Zungengrundkarzinoms

\begin{tabular}{ll}
\hline UICC-Stadium & TNM-Stadium \\
\hline Stadium I & T1 N0 M0 \\
Stadium II & T2 N0 M0 \\
Stadium III & T3 N0 M0 bis \\
& T3 N1 M0 \\
Stadium IV A & T1 bis T3 N2 M0 \\
& $\begin{array}{l}\text { oder } \\
\text { Stadium IV B }\end{array}$ \\
& jedes T N3 M0 oder \\
Stadium IV C & M1 No bis N3 M0 \\
\hline
\end{tabular}




\subsection{Grundlagen therapeutischer Möglichkeiten}

Die Therapie des Zungengrundkarzinoms ist komplex und beinhaltet verschiedene Optionen der Therapie (Steiner et al. 2003). Dazu gehören:

1) Chirurgie,

2) primäre Radio(chemo)therapie und

3) adjuvante Radio(chemo)therapie.

Diese Therapieformen können sowohl einzeln als auch kombiniert im Rahmen der kurativen Therapie angewandt werden (Steiner et al. 2003). Ziel der kurativen Therapie ist die Heilung des Menschen. Bei der kurativen chirurgischen Therapie unterscheidet man zwischen der klassischen Chirurgie von außen, der transoralen Laserchirurgie sowie, seit 2009 zugelassen, der transoralen Roboter-assistierten Chirurgie (Quon et al. 2010). In Deutschland ist die operative Resektion bei einem kurativen Ansatz die Therapie der Wahl. Ziel der chirurgischen Therapie ist die komplette Resektion des primären Tumors. Ein durch die Resektion entstandener Defekt kann unterschiedlich verschlossen werden. Zur Defektdeckung gehören der primäre Verschluss und Rekonstruktionen mit unterschiedlichen freien oder gestielten Transplantaten (Bootz 2000). Bei der Strahlentherapie gibt es im Grunde drei verschiedene Anwendungsmöglichkeiten:

1) primäre perkutane Radiotherapie,

2) adjuvante perkutane Radiotherapie nach Operation und

3) die Brachytherapie, meist als palliative Therapie.

Die Strahlentherapie kann bei inoperablen Tumoren auch als definitive Therapie angewandt werden mit dem Ziel des Funktionserhaltes einzelner Organe (Myers et al. 2012). Die interstitielle Brachytherapie mit der Anbringung kleiner Schläuche oder Nadeln an oder in den Tumor und anschließendem Einleiten einer radioaktiven Bestrahlungsquelle, z. B. Iridium-192, (Afterloading) erfolgt als Primärtherapie bei kleinen Tumoren oder nach perkutaner Radiotherapie zur lokalen Dosiserhöhung (Boost) (Strnad et al. 2013). Lokoregionär fortgeschrittene Tumoren werden meist primär operiert und postoperativ bestrahlt. Alternativ kann in besonderen Fällen eine primäre Radio(chemo)therapie in Betracht gezogen werden (Bootz 2000). Lokoregionäre Rezidive bei nicht vorbestrahlten Patienten werden primär bestrahlt (Bootz 2000). 


\subsubsection{Operative Therapie in frühen Stadien des Zungengrundkarzinoms}

Die Resektion einer Zungengrundläsion kann durch transoraler Laserresektion mittels Kohlendioxid $\left(\mathrm{CO}_{2}\right)$-Lasergerät erfolgen. Diese Therapieform wird in frühen Tumorstadien bevorzugt (Odell et al. 2008).

Sie erfolgt jedoch auch in fortgeschrittenen Stadien (Haughey et al. 2011). Mit dem Roboter-assistierten Verfahren können Oropharynx-Tumoren ebenfalls transoral ohne laterale Pharyngotomie oder Kieferspaltung R0 reseziert werden (Quon et al. 2010). Die Vorteile der Roboter-assistierten Verfahren sind z.B. eine präzise Darstellung des Tumors und ein optimaler Zugang zum Tumor. Der Nachteil sind die hohen Kosten (Chauhan et al. 2014).

\subsubsection{Primäre Radiotherapie in frühen Stadien}

In den Stadien I und II bildet die primäre alleinige Radiotherapie, wenn Kontraindikationen gegenüber einer Operation vorliegen, die zweite Säule der kurativen Therapie (Bootz 2000). In frühen Tumorstadien erfolgt die konventionelle Strahlentherapie mit 66 bis 70 Gy (Duvvuri und Meyers 2009). Bei frühen Stadien des Zungengrundkarzinoms stehen die Einzeltherapien Operation oder Strahlentherapie eher in Konkurrenz zueinander. Bei der Therapieentscheidung sind das Alter, der Allgemeinzustand und der Therapiewunsch des Patienten zu berücksichtigen. Bei jüngeren Patienten in frühen Stadien mit höherer Lebenserwartung ist es sinnvoll, die Radiotherapie zurückhaltend anzuwenden, da diese eventuell noch in der Zukunft notwendig sein könnte (Odell et al. 2008). 


\subsubsection{Operative Therapie in fortgeschrittenen Stadien}

Wird in fortgeschrittenen Stadien bei resektablen Tumoren eine operative Therapie angestrebt, kann hier der Tumor ebenfalls transoral erreicht werden (Steiner et al. 2003). Im Stadium T3 kann neben der transoralen Resektion eine transzervikale Resektion notwendig sein. Eine transzervikale Resektion kann ebenfalls mit dem Laser erfolgen (Duvvuri und Meyers 2009). Eine transzervikale Resektion erfolgt über laterale Pharyngotomie. In besonderen Fällen kann eine transorale Resektion mit dem $\mathrm{CO}_{2}$-Laser stattfinden. Nach Steiner et al. (2003) gab es gute funktionelle Ergebnisse nach Anwendung des $\mathrm{CO}_{2}$-Lasers in fortgeschrittenen Stadien. Die Ergebnisse von Steiner et al. (2003) zeigten ein höheres Risiko für bleibende Schluckstörungen bei Resektionen von ausgedehnten Infiltrationen von Halsgewebe und Strukturen, die für das Schlucken wichtig sind (supraglottischer Bereich, präepiglottischer Bereich, laterale Wand des Oropharynx). In Fällen ausgedehnter Resektionen sollte aus funktionellen Gründen eine Rekonstruktion des Defektes erfolgen.

Die Rekonstruktion, die nach Resektionen im Bereich des Zungengrundes am häufigsten angewandt wird, ist der Unterarmlappen. Das Radialistransplantat eignet sich aufgrund von Eigenschaften wie geringer Gewebsdicke, ausreichender Größe, langem Gefäßstiel und optimalem Gefäßkaliber für Rekonstruktionen im Kopf-HalsBereich (Pierre et al. 2014).

\subsubsection{Primäre Radio(chemo)therapie in fortgeschrittenen Stadien}

In den UICC-Stadien III und IV A und B kann alternativ zu einer Operation eine primäre Radio(chemo)therapie durchgeführt werden (Bootz 2000). Die definitive Strahlentherapie erfolgt, wenn eine Operation nicht möglich ist. Da in Deutschland eine Operation bevorzugt wird, erfolgt die primäre Radio(chemo)therapie meist in fortgeschrittenen Stadien bei inoperablen Tumoren (Kalogeridi et al. 2014). Aufgrund der schlechten Heilungschancen des Zungengrundkarzinoms erfolgte das Einbinden zytostatischer Substanzen als Einzelsubstanz oder als Kombination.

Die bei Zungengrundtumoren vorrangig eingesetzten Chemotherapeutika sind platinhaltige Zytostatika (Cisplatin und Carboplatin) (Bootz 2000, Pederson et al. 2010). Bei fortgeschrittenen Tumoren erfolgt eine intensivierte (hyperfraktionierte) Strahlentherapie mit 70 bis $80 \mathrm{~Gy}$ innerhalb von sechs bis sieben Wochen. Zervikale, klinisch nicht befallene Lymphknoten werden mit 50 bis 60 Gy bestrahlt (tägliche Fraktionen von 1,8 bis $2 \mathrm{~Gy}$ ) (Fu et al. 2000). Zur Verbesserung der 
Resultate erfolgt die intensitätsmodulierte Strahlentherapie (IMRT). Bei der IMRT wird der Tumor aus verschiedenen Richtungen bestrahlt und die Dosis an das Zielvolumen angepasst. Der Vorteil ist eine Intensivierung der Dosis am Tumor unter zusätzlicher Schonung von Risikoorganen (Lohia et al. 2014). Nach Lohia et al. (2014) waren dadurch die Nebenwirkungen wie Schluckstörungen hier geringer als bei der 3D-konformalen Strahlentherapie. $\mathrm{Zu}$ den Nebenwirkungen der Radiotherapie gehören akute und chronische Begleiterscheinungen. Zu den akuten Nebenwirkungen gehören unter anderem ein Erythem, eine Mukositis, welche erhebliche Schluckbeschwerden zur Folge haben kann und Heiserkeit.

$\mathrm{Zu}$ den chronischen Nebenwirkungen gehören unter anderem Hautatrophie, Mundtrockenheit mit demzufolge eingeschränkter Nahrungsaufnahme und Gewichtsverlust. Die 3-Jahres-Überlebensrate nach Radiochemotherapie beträgt in der Studien von Cano et al. (2008) $81 \%$ bei T1- bis T4-Tumoren. Das Gesamtüberleben betrug 80,9\%, die lokoregionäre Kontrollrate lag bei 79,9\%.

\subsubsection{Adjuvante Radio(chemo)therapie}

Eine adjuvante Radiotherapie kann beim Zungengrundkarzinom nach Operation von kleinen als auch von großen Tumoren erfolgen. Sie sollte aufgrund des sonst erhöhten Rezidivrisikos innerhalb der ersten sechs Wochen nach Operation erfolgen (Appold et al. 2009).

Vor allem das Zungengrundkarzinom ist eine Erkrankung, bei der das Rückfallrisiko als sehr hoch eingeschätzt wird, so dass in der Regel eine adjuvante Radio(chemo)therapie erfolgt (Steiner et al. 2003). Ein Vorzug der postoperativen Strahlentherapie ist die Möglichkeit der strengeren Indikationsstellung aufgrund der auf pathologisch-anatomischen Befunden begründeten Stadieneinteilung nach Operation. Indikation für die adjuvante Radio(chemo)therapie ist das Vorhandensein eines Residualtumors im Sinne einer R1- oder R2-Resektion. Die pathologisch ermittelten Tumorstadien pT2 bis pT4 sind ebenfalls ein Grund für postoperative Therapie. Ebenfalls erfolgt sie bei regionären Lymphknotenmetastasen, ferner bei Lymphknotenkapselruptur und Lymphangiosis carcinomatosa (Infiltration der Lymphgefäßbahnen durch Tumorzellen).

Bei HNO-Tumoren erwies sich 5-Fluorouracil in Kombination mit Cisplatin oder Carboplatin als wirksam für die simultane Strahlentherapie (Bootz 2000). Die Dosis, die mit der konventionellen Fraktionierung gegeben wird, mit der die Tumorregion und die befallenen Lymphknoten bestrahlt werden, beträgt 60 Gy. 
Sind Risikofaktoren vorhanden, wie z. B. positive Resektionsränder oder extrakapsuläres Tumorwachstum, erfolgt die adjuvante Strahlentherapie mit bis zu 66 Gy. Lymphknoten werden mit bis zu 50 Gy beidseits bestrahlt (Appold et al. 2009). Die Radio(chemo)therapie bietet Vorteile in Bezug auf Remissionsraten und Gesamtüberleben.

Die deutlich höheren „Akutmorbiditäten“ der Kombinationstherapie müssen dabei bedacht werden (Bootz 2000). Die alleinige Chemotherapie wird vorrangig in der Palliativmedizin, z.B. bei Patienten mit Fernmetastasen, eingesetzt (Bootz 2000). Von manchen Autoren wird die Kombinationschemotherapie von 5-Fluorouracil mit Cisplatin oder Taxanen bei nicht resektablen Tumoren als induktive Chemotherapie empfohlen (Haddad et al. 2013).

Ein Downstaging mittels neoadjuvanter Chemo- oder Radio(chemo)therapie hat sich aber nicht durchgesetzt und erfolgt bisher nur im Rahmen von Studien, z.B. in der DELOS-Studie für den Larynx (Dietz et al. 2009).

\subsubsection{Transorale Lasermikrochirurgie (TLM)}

Im Jahre 1971 begannen Strong und Jako mit der klinischen Anwendung des $\mathrm{CO}_{2-}$ Lasers im Bereich des Kehlkopfes (Zeitels und Burns 2006). Neben der Abtragung gutartiger Proliferationen und der palliativen Verkleinerung stenosierender Tumoren führten sie Resektionen von umschriebenen Stimmlippenkarzinome in kurativer Absicht durch (Ambrosch et al. 1994). Die minimal invasive Lasermikrochirurgie bedeutet eine neue Operationstechnik, bei der das Operationsgebiet transoral erreicht wird. Diese Technik erfordert optische Hilfsmittel wie Endoskope und Mikroskope (Steiner et al. 1991). Durch Herrn Prof. Dr. W. Steiner wurde 1979 der $\mathrm{CO}_{2}$-Laser in Deutschland erstmals zunächst bei Larynxtumoren eingesetzt (Steiner et al. 1991). Dann erfolgte mit zunehmender Praxis die Anwendung bei anderen Tumoren, so z.B. bei Tumoren des Hypopharynx (Steiner et al. 2001). Nach der chirurgischen Resektion erfolgt je nach Tumorstadium die postoperative adjuvante Radio(chemo)therapie (Steiner et al. 2003). Der Tumor wird bei dem intubierten Patienten in Vollnarkose mit dem $\mathrm{CO}_{2}$-Laser gemäß seiner vorliegenden Expansion entfernt (Ambrosch 2003). Das Ausmaß der Resektion entspricht der Tumorausbreitung, welche der Operateur unter dem Mikroskop visualisiert. Kleine Tumoren können in einem Stück reseziert werden. Ausgedehnte Tumoren müssen mosaikartig in mehreren Stücken reseziert werden. Durch das Schneiden des Tumors in mehrere Teile kann die Beurteilung der Tiefeninfiltration erfolgen wie z.B. 
in Knorpel, Knochen oder Halsweichteile (Ambrosch 2003). Für eine Zuordnung ist eine sorgfältige Markierung der Operationspräparate hierbei wichtig, besonders wenn die Präparate aus der Tiefe stammen. Die Präparate werden vom Pathologen lamelliert, eingebettet und vertikal zur Oberfläche angeschnitten. Beurteilt werden Infiltrationstiefe, Grading und die basale Abtragung.

Der Operateur muss in der Lage sein, das Mosaik aus den histologischen Befunden wieder zusammenzusetzen, um ein exaktes pT-Staging vornehmen zu können (Ambrosch et al. 1994). Die Schnittränder werden daher parallel zur Operation histologisch beurteilt (Psychogios et al. 2012).

\subsubsection{Vorteile der laserchirurgischen Resektion}

Das Prinzip besteht wie bei der konventionellen Chirurgie darin, den Tumor vollständig, also im onkologischen Sinne radikal, zu entfernen mit dem Vorteil der geringeren chirurgischen Radikalität. Der transorale Zugang ermöglicht, dass tumorfreie Strukturen des Halses wie Knorpel, Muskeln, Gefäße und Nerven erhalten bleiben. Strukturen, die funktionell wichtig für die Atmung, das Sprechen und Schlucken sind, werden somit nicht beschädigt. Dadurch, dass sensorische Nervenendigungen nicht verletzt werden, ist postoperativ der Schluckakt nicht so stark gefährdet wie bei der offenen Chirurgie und es kommt seltener zu Aspirationspneumonien (Ambrosch et al. 2001). Anders als bei der offenen Chirurgie kommt es bei der transoralen Chirurgie sehr selten zu Fistelbildungen (Patel et al. 2014). Eine orale Nahrungsaufnahme ist meist am ersten oder zweiten postoperativen Tag möglich (Eckel et al. 1995); eine Magensonde muss seltener gelegt werden als nach konventioneller Chirurgie (Kutter et al. 2007). Auch muss in der Regel keine Defektdeckung durch Lappenplastik erfolgen (Chauhan et al. 2014). Dadurch können Lokalrezidive früher erkannt werden. Ein entstandener Pharynxdefekt kann anschließend trotzdem mit einem Lappen, wie es in der konventionellen Chirurgie üblich ist, verschlossen werden. So werden die Vorzüge der minimal-invasiven Lasermikrochirurgie mit denen einer primären Defektdeckung kombiniert. Die Patienten können dann ebenfalls eine adjuvante Radio(chemo)therapie erhalten (Chauhan et al. 2014).

Das vergrößernde und hochauflösende Mikroskop und die optimale Ausleuchtung bieten eine präzise, intraoperative Gewebedarstellung. Das pathologische Gewebe und dessen topographische Beziehung zu den Nachbarstrukturen wie Knorpel und 
Weichteile können so besser beurteilt werden. Dies ist Grundlage für eine sichere Resektion des Tumors mit ausreichendem Sicherheitsabstand, welcher wichtig für eine bessere pathohistologische Beurteilbarkeit ist (Ambrosch et al. 1994). Der Tumor wird gemäß seiner tatsächlichen Ausbreitung reseziert, wodurch das Risiko einer zu weiten Resektion im gesunden Gewebe deutlich verringert ist. (Zbären et al. 1996).

Des Weiteren koaguliert der Laser Gefäße bis zu einem Durchmesser von $1 \mathrm{~mm}$ direkt. Dies ermöglicht eine blutungsarme Sicht unter dem Mikroskop für eine sichere Resektion. Komplikationen durch Blutverluste und Nachblutungen treten seltener auf, so dass häufiger auf Blutkonserven verzichtet werden kann (Steiner et al. 2001, Werner et al. 2002). Größere Gefäße werden weiter mittels monopolarer Kauterisierung oder Gefäßclipping gestillt. Da es trotz großer Wunden selten zu Nachblutungen kommt, kann mit einem minimalen Risiko operiert werden, auch bei Patienten, die an einer Blutgerinnungsstörung leiden (Kremer und Schlöndorff 2001, Werner et al. 1995). Durch eine tierexperimentelle Untersuchung von Werner et al. (1995) über die Wirkung des Lasers auf Lymphgefäße zeigte sich, dass beim Schnitt durch den Tumor eine Versiegelung der Lymphgefäße im Bereich des Schnittrandes erfolgt. Dies bedeutet, dass, obgleich mit dem Laser durch den Tumor geschnitten wird, eine Tumorzelleinschwemmung in die angeschnittenen Lymphgefäße nicht begünstigt wird. Trotz des Schneidens durch den Tumor ist kein gehäuftes Auftreten von Metastasen zu beobachten (Werner et al. 1995).

Auf eine Tracheotomie kann ebenfalls häufig verzichtet werden, da sich postoperative Schleimhautödeme seltener ausbilden (Kutter et al. 2007). Die Liegedauer ist im Zusammenhang mit diesen Faktoren verkürzt (Grant et al. 2009), was für die Patienten ein Vorteil ist (Kutter et al. 2007). Die Laserchirurgie trägt dazu bei, dass durch die Erhaltung funktioneller Strukturen die Lebensqualität der Patienten stark verbessert wird (Steiner et al. 1991). Die endoskopische Resektion hat eine niedrigere Morbidität als die offene Chirurgie oder Radiotherapie (Eckel et al. 1995). 


\subsection{Prognose nach kurativer Therapie}

Die Prognose des Zungengrundkarzinoms ist trotz aller medizinischer Fortschritte nach wie vor schlecht (Steiner et al. 2003). Dies liegt am häufig schon fortgeschrittenem Stadium bei Diagnosestellung, da Zungengrundkarzinome lange Zeit klinisch stumm bleiben können (Camp et al. 2009). Mehr als die Hälfte aller Patienten hat bei der Diagnose bereits Lymphknotenmetastasen (Steiner et al. 2003). Kotwall et al. (1987) beobachteten die Fernmetastasierung bei Plattenepithelkarzinomen des oberen Verdauungstraktes und fanden eine der höchsten Raten an okkulten Fernmetastasen bei Zungengrundkarzinomen. Die Patienten sterben meist aufgrund der Lymphknotenmetastasierung, Fernmetastasierung (hauptsächlich in Leber und Lunge), aufgrund von Zweittumoren (vor allem in Bronchien und Ösophagus) oder wegen der Organschäden in Leber, Herz und Lungen aufgrund des chronischen Alkohol- und Nikotinabusus (Steiner et al. 1991). Während in den 50er- und 60er Jahren die Fünf-Jahres-Überlebensrate bei $20 \%$ lag, konnte diese im darauffolgenden Jahrzehnt durch Fortschritte in der Therapie auf 30\% gesteigert werden (Steiner et al. 2003). Nach Guntinas-Lichius et al. (2009) besteht beim Zungengrundkarzinom eine Fünf-Jahres-Überlebensrate von 17\% bis 40\%, im Durchschnitt bei 25\% (Stadium I: 55-68\%, Stadium II: 50\%, Stadium III: 28-37\%, Stadium IV: 0-18\%). Ziel ist es bei der ungünstigen Prognose, unabhängig von unterschiedlichen Therapien, eine optimierte Lebensqualität zu erreichen.

\subsection{Therapie der regionären Lymphabflussgebiete beim Zungengrund- karzinom}

Da bei Zungengrundkarzinomen häufig schon früh Halslymphknotenmetastasen bestehen, folgt im Anschluss an die Laserresektion des Primärtumors meist eine Neck-Dissection (Steiner et al. 2003). Diese kann simultan oder ein bis zwei Wochen versetzt stattfinden (Bootz 2000). Bis in die späten 1960er Jahre blieb die klassische radikale Neck-Dissection (RND) der unbestrittene Standard. Hier erfolgt die Ausräumung aller fünf Lymphknotengruppen und die Entfernung wichtiger nichtlymphatischer Strukturen (M. sternocleidomastoideus, V. jugularis interna und N. accessorius). Im Jahr 1963 wurde die Methode entwickelt, eine oder mehrere nichtlymphatische Strukturen zu erhalten, die bei der radikalen Neck-Dissection entfernt wurden. Neben funktionellen und kosmetischen Vorteilen erlaubte das Verfahren die gleichzeitige bilaterale Operation, so dass die Indikation zur elektiven 
Neck-Dissection erweitert wurde. Diese Operation mit Entfernung der Lymphknoten der Level I bis V und Bewahrung von mehreren nichtlymphatischen Strukturen wurde 1991 von der American Academy of Otolaryngology - Head and Neck Surgery als modifizierte radikale Neck-Dissection (MRND) definiert (Ambrosch et al. 2001). Seit den frühen 80er Jahren wird die selektive Neck-Dissection für Karzinome des oberen Aerodigestivtrakts bei den Kategorien N0 bis N1 angewandt (Canis et al. 2012). Bei der selektiven Neck-Dissection werden mindestens zwei, aber weniger als fünf Lymphknotengruppen entfernt (Bootz 2000). Nichtlymphatische Strukturen werden weitgehend erhalten (Bootz 2000). Beim klinischen N0-Stadium wird meist eine selektive Neck-Dissection durchgeführt. Eine abwartende Haltung kann bei kooperativen Patienten in frühen Stadien angebracht sein, wenn nahe beieinander liegende Nachsorgeuntersuchungen möglich sind (z. B. Sonographie und/oder CT, MRT des Halses) (Bootz 2000). In der Studie von Canis et al. (2012) gab es keine signifikanten Unterschiede im Überleben in frühen Stadien eines Plattenepithelkarzinoms des oberen Aerodigestivtrakts im Vergleich mit und ohne Neck-Dissection. Mit den Patienten sollten ausführlich Vor- und Nachteile besprochen werden. Allerdings muss das Risiko okkulter Metastasen (15\%) betrachten werden. Patienten, die nicht regelmäßig untersucht werden können, sollten eine selektive Neck-Dissection erhalten (Canis et al. 2012). Außerdem kann die histologische Untersuchung der Lymphknoten bei der weiteren adjuvanten Therapieentscheidung von Bedeutung sein (Canis et al. 2012).

Bei Patienten in den Stadien III und IV, bei denen eine chirurgische Therapie angewendet wird, erfolgt bei positivem Halslymphknotenbefund die Neck-Dissection von Level I bis V. Bei fortgeschrittenen Stadien ohne Nachweis von Lymphknotenmetastasen sollte eine selektive Neck-Dissection der Regionen II, III und IV durchgeführt werden (Odell et al. 2008). 


\subsection{Ziel der Arbeit}

Bereits veröffentlichte Daten haben gezeigt, dass bei Zungengrundtumoren mittels organerhaltender Lasermikrochirurgie und anschließender adjuvanter Strahlentherapie gute onkologische Ergebnisse mit hohen Raten an Organerhalt erreicht werden können (Steiner et al. 2003). Ziel der Arbeit ist es, die funktionellen und onkologischen Behandlungsergebnisse von Patienten mit Zungengrundkarzinom zu untersuchen. Dabei handelt es sich um ein relativ heterogenes Kollektiv (Tumorstadien I bis IV), bei denen die Therapie aus organerhaltender Lasermikrochirurgie mit und ohne adjuvanter Radio(chemo)-therapie bestand.

Dabei werden retrospektiv zum einen die onkologischen Ergebnisse in Bezug auf das Gesamtüberleben, die lokoregionäre Tumorkontrolle, rezidivfreie Überlebenszeit und das tumorspezifische Überleben erhoben und zum anderen Komplikationen z.B. in Bezug auf Organfunktionen wie Schlucken analysiert. 


\section{Patienten und Methoden}

\subsection{Beschreibung des Patientenkollektivs}

\subsubsection{Einschlusskriterien}

Im Rahmen dieser Arbeit wurden 312 Patienten analysiert, welche zwischen 1986 und 2011 mit einem Zungengrundkarzinom in der Klinik für Hals-Nasen-Ohrenheilkunde der Universitätsmedizin Göttingen transoral mittels Lasermikrochirurgie behandelt wurden. Der mediane Nachbeobachtungszeitraum betrug 51 Monate (Zeitspanne: vier bis 253 Monate). In die Studie wurden bisher unbehandelte Patienten mit der Erstdiagnose eines Plattenepithelkarzinoms des Zungengrundes eingeschlossen. Bei keinem Patienten in dieser Studie wurde eine primäre Radio(chemo)therapie durchgeführt.

\subsubsection{Ausschlusskriterien}

Ausgeschlossen wurden Patienten mit Vorliegen eines simultanen Zweittumors $(n=14)$ oder simultanen Fernmetastasen $(n=8)$. Der Nachweis einer Histologie, welche nicht einem Plattenepithelkarzinom entsprach $(n=19)$, führte ebenfalls zum Ausschluss aus der Studie. Ferner wurden Patienten herausgenommen,

die eine primäre Radio(chemo)therapie erhalten hatten $(n=62)$, bei denen Lymphknotenmetastasierungen in Stadium N3 vorlagen $(n=15)$ sowie bei denen der Tumor ein Rezidivtumor war, der primär auswärts behandelt wurde ( $n=14)$, und bei denen eine simultane Zweittherapie vorlag $(n=14)$. Zweittumoren $(n=65)$ lagen wie folgt vor: Mandeln $(n=10)$, Mundboden $(n=7)$, Hypopharynx $(n=11)$, Kehlkopf $(n=8)$, Speiseröhre $(n=6)$, Lunge $(n=8)$, Brust $(n=2)$, Prostata $(n=6)$, Schilddrüse $(n=1)$. Des Weiteren wurden Patienten nicht berücksichtigt, bei denen kein kurativer Therapieansatz mehr bestand $(n=33)$.

Damit verblieben 82 Patienten, die zwischen 1986 und 2011 mit einem unbehandelten Plattenepithelkarzinom des Zungengrundes in kurativer Absicht mit $\operatorname{dem} \mathrm{CO}_{2}$-Laser therapiert wurden, in der Studie. 


\subsubsection{Alter- und Geschlechtsverteilung}

Das Kollektiv bestand aus 82 Patienten und teilte sich auf in 67 Männer (82\%) und 15 Frauen (18\%). Das Durchschnittsalter der in die Studie aufgenommenen Patienten betrug $58 \pm 11$ Jahre mit einer Spanne von 31 bis 86 Jahren.

\subsection{Operationstechniken}

Die Operationen wurden in Allgemeinanästhesie durchgeführt.

Die kontinuierliche Beatmung erfolgte über einen Endotrachealtubus. Bei einigen Patienten, bei denen im präoperativen Staging palpatorisch oder sonographisch Halslymphknotenmetastasen festgestellt wurden, wurde im Anschluss an die Operation eine selektive Neck-Dissection durchgeführt. Eine modifizierte radikale Neck-Dissection wurde in zwei Fällen (2\%) durchgeführt. Wenn histologische Resektionsränder in intraoperativen pathologischen Analysen positive oder keine sicheren Ergebnisse zeigten, wurden Nachresektionen durchgeführt, um tumorfreie Resektionsränder zu erreichen.

\subsection{Verteilung der Stadien}

Die Karzinome teilten sich nach den UICC-Stadien (Sobin und Compton 2002) folgendermaßen auf:

- 1 Patient in Stadium I (1\%),

- 6 Patienten in Stadium II (7\%),

- 14 Patienten in Stadium III (17\%) und

- 61 Patienten in Stadium IV (75\%). 


\subsection{Therapie des Primärtumors}

Bei sechs Patienten (7\%) erfolgte ausschließlich die transorale Lasermikrochirurgie. Bei 31 (38\%) der 82 Patienten bestand die Behandlung aus einer laserchirurgischen Operation und einer ein- oder beidseitigen Neck-Dissection.

44 Patienten (54\%) wurden einer laserchirurgischen Behandlung zugeführt, gefolgt von einer ein- oder beidseitigen Neck-Dissection und einer daran anschließenden Radio(chemo)therapie. Ein Patient (1\%) wurde einer laserchirurgischen Behandlung zugeführt, gefolgt von einer daran anschließenden Strahlentherapie. Die folgende Tabelle fasst die durchgeführten Therapieoptionen zusammen:

Tabelle 5: Therapie des Primärtumors (ND $=$ Neck-Dissection, $n=$ absolute Anzahl der Patienten, [\%] = relative Anzahl der Patienten, $\mathrm{RT}=$ Radiotherapie)

\begin{tabular}{lll}
\hline Therapie & $\mathbf{n}$ & [\%] \\
\hline Laser allein & 6 & 7 \\
Laser + ND & 31 & 38 \\
Laser + ND + RT & 44 & 54 \\
Laser + RT & 1 & 1 \\
\hline
\end{tabular}

\subsection{Präoperative Diagnostik und Therapie der Halslymphknoten}

Die Sonogragraphie ist für das Lymphknotenstaging am besten geeignet bei erhöhter Sensitivität (Rainer et al. 1993). Bei Patienten mit Tumorstadium pT1cN0 wurde ein engmaschiges Follow-up betrieben im Rahmen der Wait-and-seeStrategie.

Wenn der Patient sich mit fortgeschrittener primärer Erkrankung vorstellte, die Tumorinfiltrationstiefe mehr als $3 \mathrm{~mm}$ betrug oder Halslymphknotenmetastasen aufgrund des palpatorischen oder präoperativ bildgebenden Befundes wahrscheinlich waren, wurde eine ein- oder beidseitige Neck-Dissection (vor allem selektive Neck-Dissection) durchgeführt. Eine bilaterale Neck-Dissection erfolgte bei beidseitigem Lymphknotenbefall bei fortgeschrittenen, die Mittellinie erreichenden Tumoren und bei einseitigem Lymphknotenbefall, wenn keine adjuvante Therapie geplant war. Insgesamt erhielten 75 Patienten (91\%) zusätzlich zur Therapie des Primärtumors eine Neck-Dissection. Bei 38 Patienten (51\%) erfolgte die NeckDissection bilateral und in 37 Fällen (49\%) unilateral. Mit Ausnahme eines 
Patienten erfolgte die Ausräumung der Halsregionen II und III. Gegebenenfalls wurden zusätzlich die Halsregionen I (23 Patienten) und/oder IV (24 Patienten) und/oder V (drei Patienten) ausgeräumt.

Zwei Patienten (2\%) erhielten eine modifizierte radikale Neck-Dissection aller Halsregionen. Histopathologisch positive Lymphknoten lagen bei 55 Patienten $(71 \%)$ vor, von denen bei $29(38 \%)$ mehrere bilateral positive Halslymphknoten vorhanden waren.

\subsection{Adjuvante Radio(chemo)therapie}

45 der 82 Patienten (18\%) unterzogen sich zusätzlich zur Chirurgie des Primärtumors und der ein- oder beidseitigen Halsoperation im Anschluss an die operative Therapie einer adjuvanten Bestrahlung. Die adjuvante kombinierte Radio(chemo)therapie wurde in 19 Fällen (23\%) durchgeführt.

Eine adjuvante Radio(chemo)therapie wurde in Fällen fortgeschrittener Primärtumoren, z. B. bei Stadium N2a/b/c, durchgeführt oder wenn die histopathologische Untersuchung extrakapsuläres Tumorwachstum und/oder lymphatische Mikrometastasen sowie Fernmetastasen ergab. Die Patienten, die von April 1988 bis Dezember 1993 eine Radio(chemo)therapie bekamen (11 Patienten), erhielten zwei Fraktionen pro Tag, die von sechsstündigen Intervallen getrennt waren. Jede Fraktion bestand aus $210 \mathrm{cGy}\left(1.25 \mathrm{MV}{ }^{60} \mathrm{CO}\right)$, denen täglich eine Dosis von $50 \mathrm{mg} / \mathrm{m}^{2}$ Carboplatin intravenös vorangestellt wurde. Insgesamt wurde eine Strahlendosis von 5670 cGy, mit welcher Hals- und Primärtumor bestrahlt wurden, über sechs Wochen fraktioniert angewendet. Eine Pause von zwei Wochen wurde zwischen den zwei letzten Wochen der Behandlung eingeplant.

Die Behandlung wurde vier Tage pro Woche angewandt. Das Zielvolumen des ersten Tages (gegeben am Morgen), mit dem der Primärtumor und der obere Hals bestrahlt wurden, wurde mit zwei parallelen, gegenüberliegenden Photonenfelder erreicht. In der zweiten Fraktion (gegeben am Nachmittag) wurde das Rückenmark ausgeblockt und Elektronen (9 MeV) wurden verwendet, um den hinteren Halsbereich mit seinen Lymphknoten zu erreichen. Das Rückenmark wurde bis maximal 25,2 Gy bestrahlt. Der untere Hals wurde über ein ventrales Stehfeld mit bis zu 5.250 cGy bestrahlt. Diese Dosis wurde auf $3 \mathrm{~cm}$ Herdtiefe erzielt. Cisplatinbasierte Chemotherapie wurde gleichzeitig in drei Fällen gegeben.

Von Januar 1995 bis Dezember 2004 (bei 28 Patienten) wurde die fraktionierte Strahlentherapie (2 Gy/d, fünfmal pro Woche), über zwei parallele, gegen- 
überliegende Gegenfelder (Photonen) abgestimmt, zunächst bis zu einer maximalen Gesamtdosis von 50 Gy. Ab einer Strahlendosis von 36 Gy wurde das Rückenmark ausgeblockt, Elektronen wurden verwendet, um die Dosis im hinteren Halsbereich zu sättigen. Die Bestrahlung der unteren Halslymphknoten sowie der supraklavikulären Lymphknoten erfolgte über ein ventrales Stehfeld bis zu einer Eindringtiefe von $3 \mathrm{~cm}$. Die Bestrahlung wurde CT-basiert, 3D-konformal, mit einer Gesamtdosis von 60 Gy auf die ehemalige Primärtumorregion und die Lymphknotenregionen mit histopathologischen Lymphknoten realisiert. Das Rückenmark wurde mit maximal 45 Gy bestrahlt. Die begleitende Chemotherapie wurde bei elf Patienten angewandt.

Von Dezember 2004 bis Dezember 2007 wurden sechs Patienten ebenfalls mit einer normofraktionierten Radiotherapie (Dosis pro Fraktion: 2 Gy/d, fünf Tage pro Woche) CT-basiert, 3D-konformal bestrahlt. Die ehemalige Primärtumorregion und befallene Lymphknoten sowie potenzielle Abflussgebiete auf beiden Seiten des Halses, einschließlich der supraklavikulären und zervikalen Region, wurden mit 50 Gy in einer ersten Phase gefolgt von einem Boost bis zu einer Gesamtdosis von 64 Gy in der zweiten Phase bestrahlt. Das Rückenmark wurde mit einer Maximaldosis von 45 Gy bestrahlt. Darüber hinaus wurde eine Cisplatin-basierte Chemotherapie begleitend bei fünf Patienten gegeben.

\subsection{Nachsorgeuntersuchungen}

Die Nachsorgeuntersuchungen nach abgeschlossener kurativer Therapie fanden an der HNO-Klinik statt. Diese wurden in den ersten zwei Jahren zunächst alle zwei bis drei Monate, danach alle sechs Monate durchgeführt. Die Bildgebung (CT oder MRT) wurde in den ersten zwei Jahren der Nachsorge jährlich wiederholt, um ein Tumorrezidiv frühzeitig zu erkennen. Die Nachsorgeuntersuchung beinhaltete eine HNO-Untersuchung, endoskopische Untersuchung sowie einen Ultraschall. 


\subsection{Statistische Methoden}

Die Kaplan-Meier-Methode (Kaplan und Meier 1958) wurde zur Kalkulation der Überlebensdaten herangezogen. Zu den erhobenen statistischen Errechnungen gehörten:

1) lokale Kontrolle,

2) Gesamtüberleben,

3) rezidivfreies Überleben.

Postoperative Follow-up-Daten waren bei allen Patienten verfügbar. Zur Bestimmung der lokalen Kontrolle wurden nur lokale Rezidive als Ereignisse gezählt. Lebende Patienten ohne Lokalrezidiv oder verstorbene Patienten, unabhängig von der Todesursache, wurden nicht betrachtet. Die Definition des sogenannten lokalen Rezidivs beinhaltete das Carcinoma in situ sowie Karzinome, die nach Abschluss der Primärbehandlung auftraten.

Die Überlebenszeit wurde als Intervall zwischen dem Zeitpunkt der Operation und dem Datum der letzten Beratung oder dem Datum des Todes definiert. Für die Statistik der rezidivfreien Überlebenszeit wurden interkurrente Todesfälle, Todesfälle aufgrund von Zweittumoren und lebende Patienten ohne Rezidiv als zensiert betrachtet. In die Statistik eingeschlossen wurden lokale und regionäre Rezidive, Fernmetastasen und Todesfälle aufgrund der Erkrankung. 


\section{Ergebnisse}

\subsection{Onkologische Ergebnisse}

\subsubsection{Lokale Rezidivkontrolle}

Im Folgenden werden die Kurven der Fünf-Jahres-Daten der lokalen Rezidivkontrolle nach Kaplan-Meier (Kaplan und Meier 1958) dargestellt.

Die Abbildung 3a zeigt die lokale Rezidivfreiheit des Gesamtkollektivs. Die FünfJahres-Daten für die lokale Kontrolle des Gesamtkollektivs betrugen 84\%. Bei 84\% der Patienten trat also nach fünf Jahren kein Lokalrezidiv auf. Im Gesamtkollektiv sind infolgedessen bei insgesamt elf Patienten (13\%) Lokalrezidive aufgetreten.

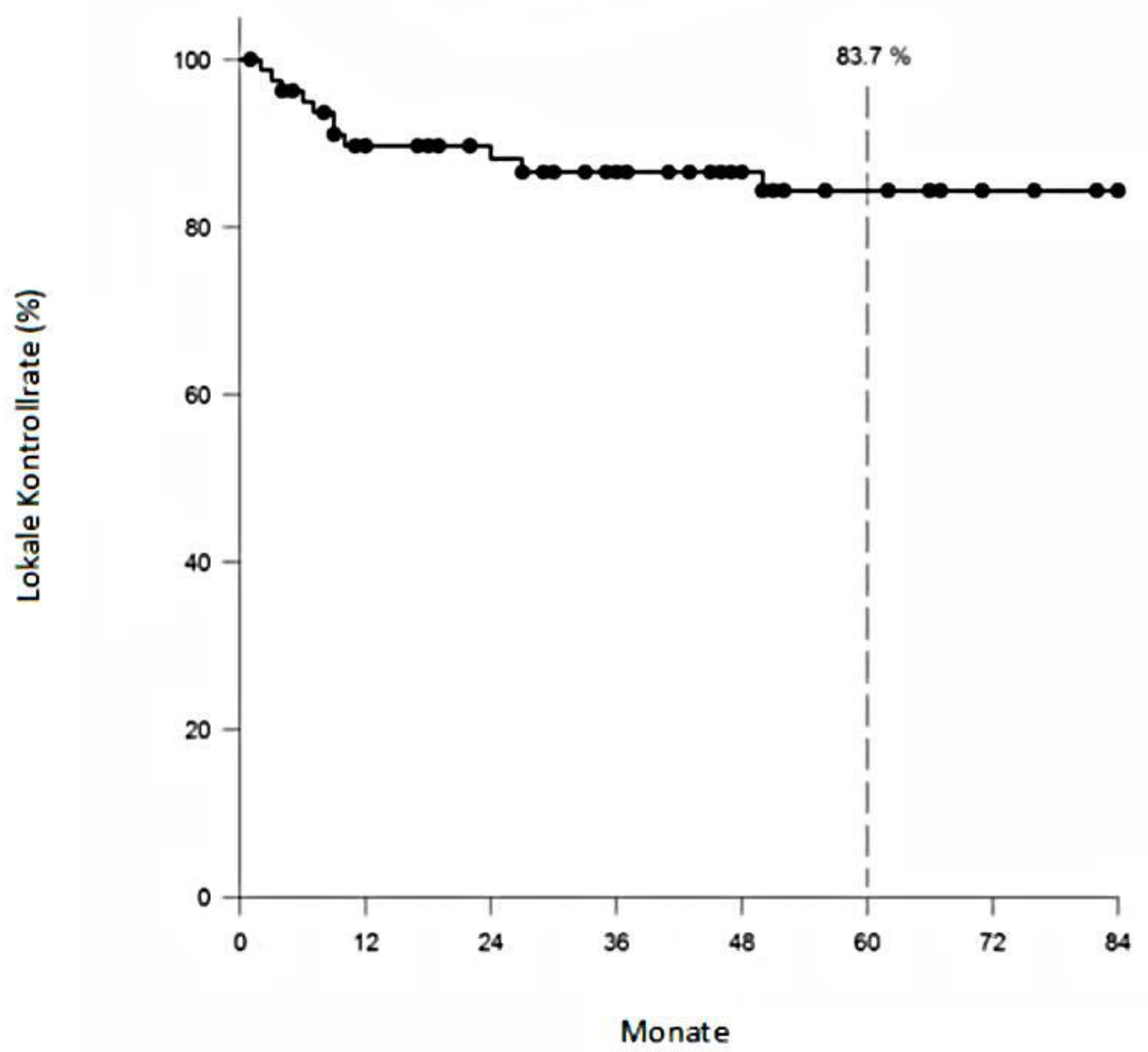

Abbildung 3a: Lokale Rezidivfreiheit des Gesamtkollektivs 
Die Abbildung 3b zeigt die lokale Rezidivfreiheit TNM-bezogen. Die T-Stadiumbezogene lokale Kontrolle nach fünf Jahren betrug 94\% für T1 bis T2, 78\% für T3 und $81 \%$ für das Stadium T4.

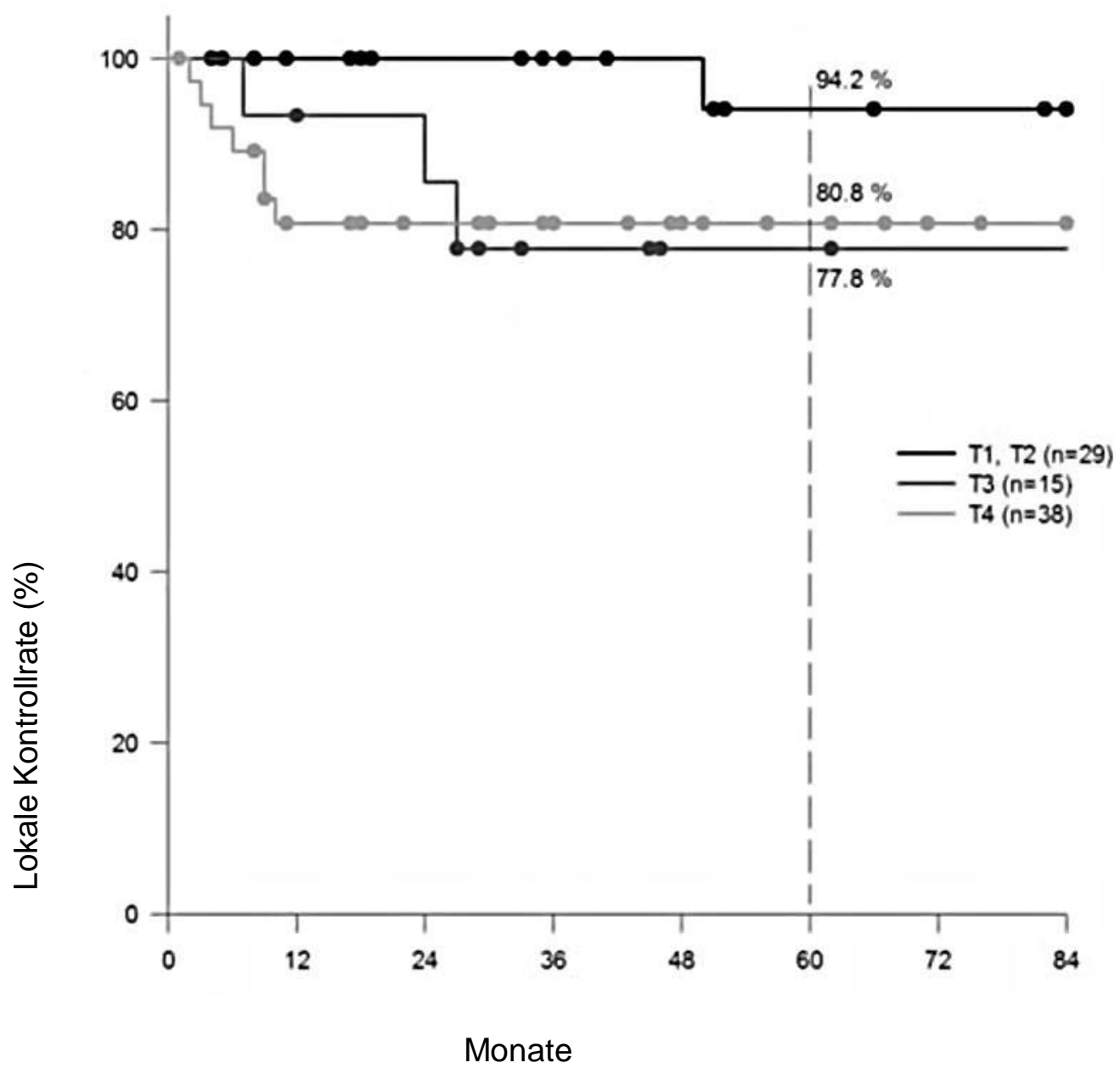

Abbildung 3b: Lokale Rezidivfreiheit, TNM-bezogen 
Die Tabelle 6 zeigt die Anzahl der Lokalrezidive auf das TNM-Stadium bezogen. Von fünf Patienten im pT1-Stadium wurde bei einem ein Lokalrezidiv beobachtet. Bei den 24 Patienten im pT2-Stadium wurden keine Lokalrezidive beobachtet. Bei drei von 15 Patienten (20\%) im pT3-Stadium und sieben von 38 Patienten (18\%) im pT4-Stadium traten im Laufe der Nachbeobachtungszeit Lokalrezidive auf.

Tabelle 6: Lokalrezidive TNM-bezogen

\begin{tabular}{lll}
\hline Stadium & $\mathbf{N}=\mathbf{8 2}$ & Lokalrezidiv \\
\hline pT1 & 5 & $1(20 \%)$ \\
pT2 & 24 & 0 \\
pT3 & 15 & $3(20 \%)$ \\
pT4 & 38 & $7(18 \%)$ \\
\hline
\end{tabular}




\subsubsection{Gesamtüberleben}

In Folgenden werden die Kurven der Fünf-Jahres-Daten des Gesamtüberlebens nach Kaplan-Meier (Kaplan und Meier 1958) dargestellt.

Der Nachbeobachtungszeitraum betrug vom Diagnosezeitpunkt an im Median 51 Monate (bei einer Spanne von vier bis 253 Monaten). Die Abbildung 4a zeigt das Gesamtüberleben des Gesamtkollektivs. Die Fünf-Jahres-Gesamtüberlebensrate betrug $59 \%$.

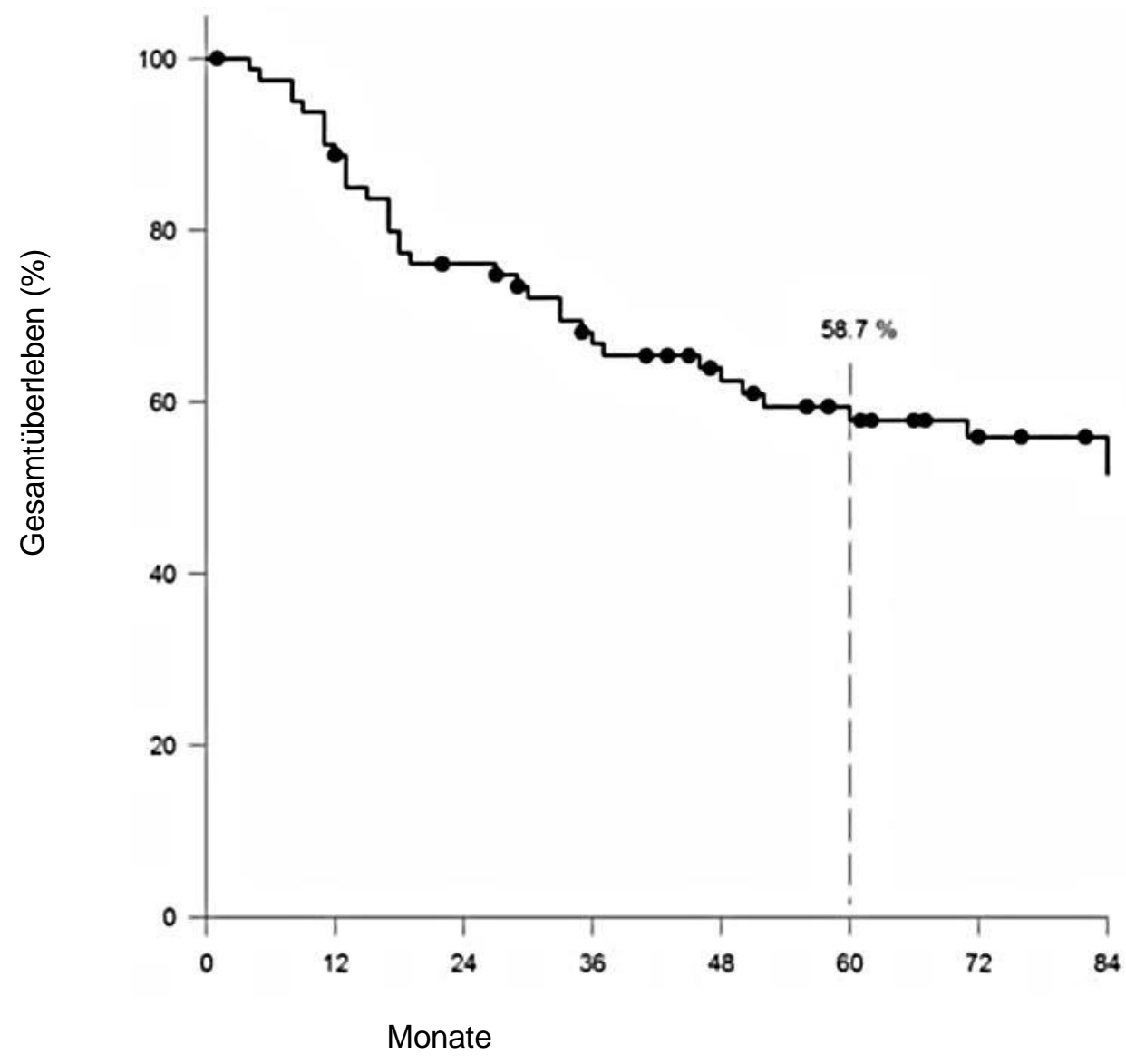

Abbildung 4a: Gesamtüberlebensrate des Gesamtkollektivs 
Das UICC-Stadium-bezogene Gesamtüberleben, in der Abbildung 4b dargestellt, lag bei $70 \%$ für die Stadien I bis II, bei $44 \%$ für das Stadium III und $58 \%$ für das Stadium IV.

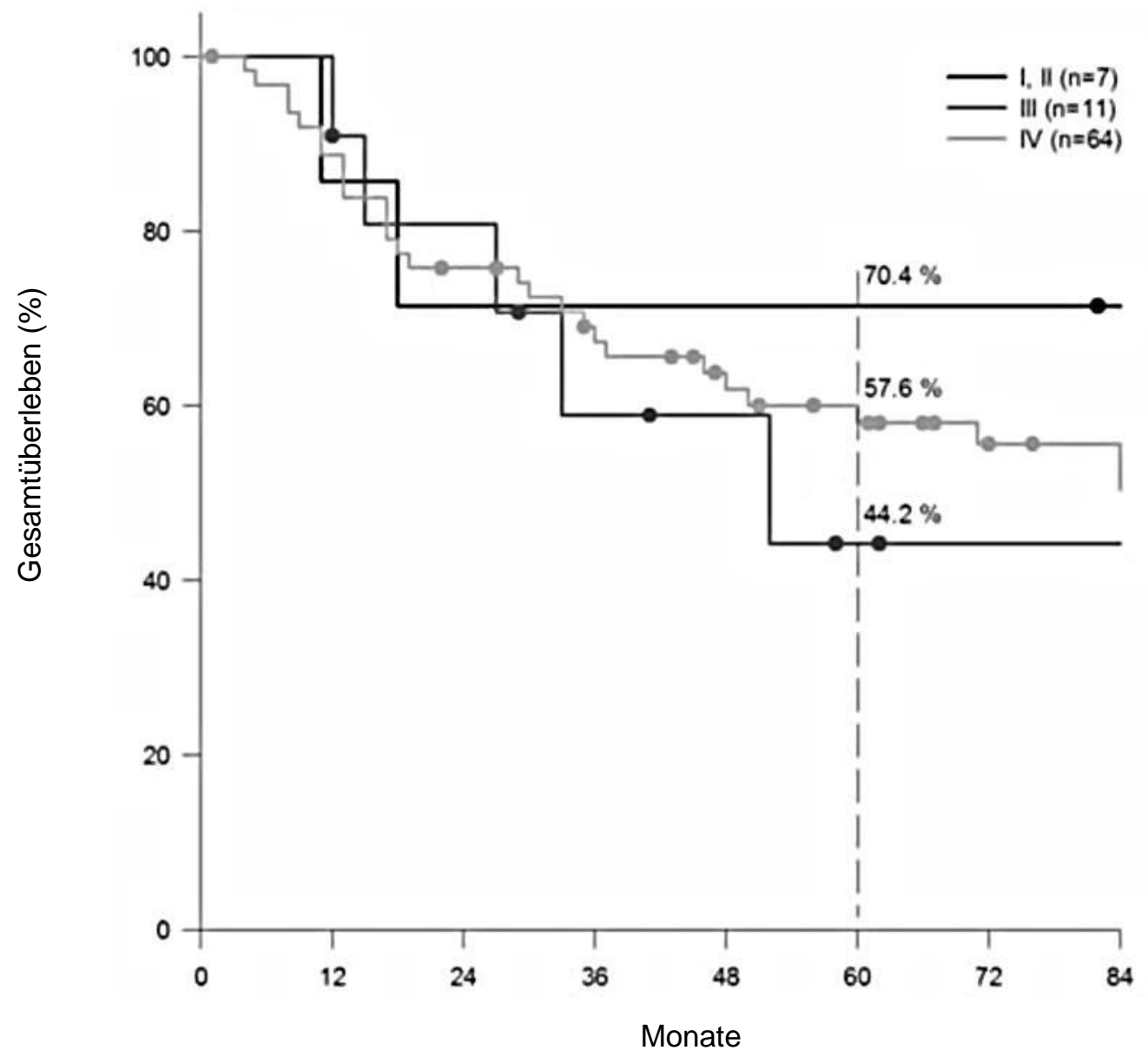

Abbildung 4b: Gesamtüberlebensrate nach UICC-Stadium 


\subsubsection{Rezidivfreies Überleben}

Es werden die Kurven der Fünf-Jahres-Daten des rezidivfreien Überlebens nach Kaplan-Meier (Kaplan und Meier 1958) dargestellt.

Die Abbildung 5a zeigt das rezidivfreie Überleben des Gesamtkollektivs. Das rezidivfreie Überleben des Gesamtkollektivs betrug 69\%.

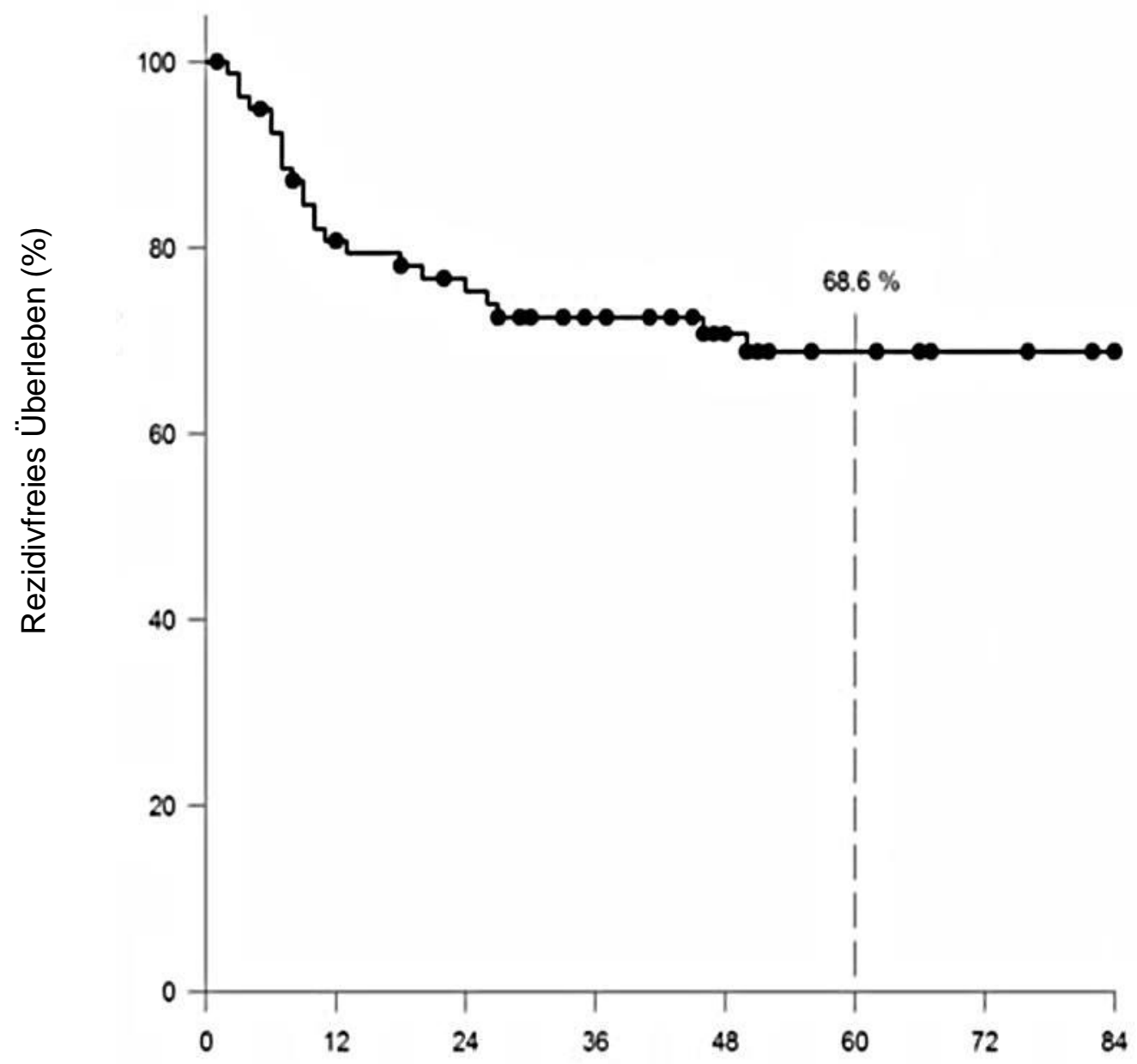

Monate

Abbildung 5a: Rezidivfreies Überleben des Gesamtkollektivs 
Das UICC-Stadium-bezogene rezidivfreie Überleben, dargestellt in Abbildung 5b, lag bei $86 \%$ für Stadium I und II, bei $54 \%$ in Stadium III und bei $69 \%$ für Stadium IV.

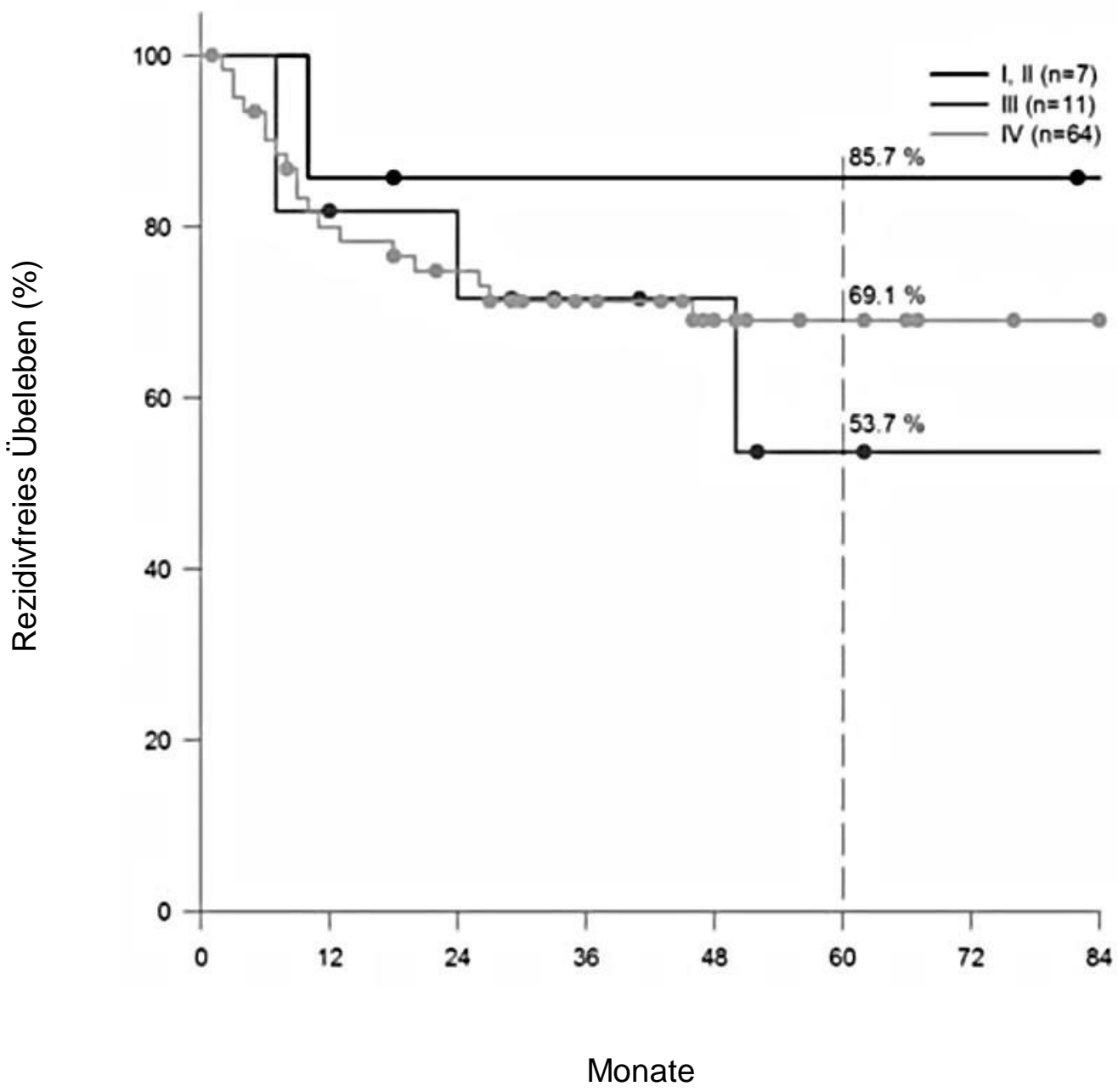

Abbildung 5b: Rezidivfreies Überleben UICC-Stadium-bezogen 
Die Ergebnisse der Unterteilung des rezidivfreien Überlebens und des Gesamtüberlebens des Gesamtkollektivs nach zwei, drei und fünf Jahren sind Tabelle 7 zu entnehmen. Das Zwei-Jahres-Gesamtüberleben bzw. das rezidivfreie Überleben betrug jeweils $76 \%$. Das Drei-Jahres-Gesamtüberleben und rezidivfreie Überleben betrug $67 \%$ bzw. $73 \%$. Nach fünf Jahren betrug das Gesamtüberleben 59\% und das rezidivfreie Überleben $69 \%$.

Tabelle 7: Gesamt- und rezidivfreies Überleben im Vergleich nach zwei, drei und fünf Jahren

\begin{tabular}{lll}
\hline Intervall & $\begin{array}{l}\text { Gesamtüberleben } \\
\text { [\%] }\end{array}$ & $\begin{array}{l}\text { Rezidivfreies Überleben } \\
{[\%]}\end{array}$ \\
\hline 2 Jahre & $76 \%$ & $76 \%$ \\
3 Jahre & $67 \%$ & $73 \%$ \\
5 Jahre & $59 \%$ & $69 \%$ \\
\hline
\end{tabular}

Die Tabelle 8 demonstriert die Rate der Lymphknotenmetastasen verteilt auf die korrespondierenden pT-Stadien. Hier zeigt sich, dass mit $54 \%$ die meisten $\mathrm{Pa}$ tienten in den Stadien pT1- bis pT4-Metastase(n) in bilateralen Lymphknoten über der Supraclaviculargrube, $6 \mathrm{~cm}$ oder weniger in größter Ausdehnung hatten (pN2). Im Vergleich wurde das Stadium pN1 bei den wenigsten Patienten diagnostiziert.

Tabelle 8: Verteilung der Lymphknotenmetastasen auf die pT-Stadien

\begin{tabular}{lllllllllll}
\hline & pT1 & [\%] & pT2 & [\%] & pT3 & [\%] & pT4 & [\%] & total & [\%] \\
\hline N0/pN0 & 1 & 1,2 & 8 & 9,8 & 4 & 4,9 & 13 & 15,9 & 26 & 32 \\
pN1 & 2 & 2,4 & 3 & 3,7 & 2 & 2,4 & 5 & 6,1 & 12 & 14 \\
pN2 & 2 & 2,4 & 13 & 15,9 & 9 & 11,0 & 20 & 24,4 & 44 & 54 \\
\hline
\end{tabular}


Die Tabelle 9 stellt die Häufigkeit an Rezidiven dar. Bei acht Patienten trat im Laufe der Nachbeobachtungszeit ein isoliert lokales, sprich nur auf den Zungengrund beschränktes Rezidiv auf. Bei sechs Patienten kam es zu isoliert regionären, also nur die regionalen Lymphknoten betreffenden Rezidiven. Bei zwei Patienten trat ein kombiniertes lokoregionäres Rezidiv auf. Ein Patient hatte eine isolierte Fernmetastase und ein Patient ein Lokalrezidiv kombiniert mit einer Fernmetastase.

Tabelle 9: Therapieversager

\begin{tabular}{ll}
\hline Therapieversager & Anzahl \\
\hline Lokalrezidiv & $8(10 \%)$ \\
Lymphknotenmetastasen ohne Lokalrezidiv & $6(7 \%)$ \\
Lokoregionäres Rezidiv & $2(2 \%)$ \\
Fernmetastasen ohne lokales Rezidiv & $1(1 \%)$ \\
Lokalrezidiv und Fernmetastasen & $1(1 \%)$ \\
insgesamt & $18(21 \%)$ \\
\hline
\end{tabular}




\subsection{Häufigkeit und Lokalisation von Zweittumoren}

Bei 67 Patienten war kein Zweitkarzinom bekannt, während bei den übrigen Patienten ein Zweitkarzinom vorlag (siehe Tabelle 10). Zweittumoren wurden bei 15 Patienten (18\%) beobachtet. Vier dieser Zweittumoren waren im HNO-Bereich. Bei elf dieser Patienten war der Zweittumor nicht in der Kopf-Hals-Region lokalisiert. Diese traten in der Lunge, Speiseröhre, Leber, im Enddarm und in der Prostata auf. Im Durchschnitt wurden die Zweittumoren 57 Monate nach der Erstdiagnose des Zungengrundkarzinoms festgestellt. Die früheste Registrierung erfolgte elf Monate nach der Diagnose des Primärtumors, die späteste nach 224 Monaten.

Tabelle 10: Art und Anzahl der Zweitkarzinome

\begin{tabular}{ll}
\hline Zweittumor & Anzahl \\
\hline kein Zweittumor & 67 \\
HNO-Zweittumor & 4 \\
Bronchialkarzinom & 5 \\
Ösophaguskarzinom & 1 \\
Rektumkarzinom & 1 \\
Analkarzinom & 1 \\
Leberkarzinom & 1 \\
Prostatakarzinom & 2 \\
\hline
\end{tabular}

\subsection{Komplikationen und funktionelle Ergebnisse}

Die Komplikationen der transoralen Lasermikrochirurgie des Zungengrundes sind im Vergleich zu anderen Techniken seltener (Steiner et al. 2003). In der Tabelle 11 sind die häufigsten Komplikationen zusammengefasst.

Nasogastrale Ernährungssonden wurden postoperativ bei 66 Patienten (80\%) benötigt und konnten nach durchschnittlich zehn Tagen entfernt werden. Bei sieben Patienten (9\%) musste eine perkutane endoskopische Gastrostomie (PEG) angelegt werden. Bei fünf Patienten (6\%) musste diese aufgrund persistierender Schluckstörungen dauerhaft (bis zum Ende des Follow-up oder Tod) verbleiben. Zwei Patienten benötigten temporäre Gastrostomien aufgrund von Aspirationsstörungen.

Nach Verbesserung der Schluckfunktion mittels logopädischer Schlucktherapie 
wurde die PEG-Sonde 12 und 28 Monate später entfernt. Magensonden und PEGSonden wurden nur dann entfernt, wenn die Patienten in der Lage waren, sich ohne jegliche klinische und radiologische Zeichen einer Aspiration zu ernähren.

Bei transoralen Zungengrundteilresektionen betrug die Rate an postoperativen Nachblutungen 13\% (elf Patienten). Bei neun Patienten (11\%) trat die Nachblutung am Zungengrund auf und bei den restlichen zwei Patienten gab es Nachblutungen im Halsbereich. Eine tödliche Nachblutung trat nicht auf. Eine operative Blutstillung war erforderlich. Diese erfolgte unter dem Pharyngoskop mittels Koagulation und/oder Clipping.

2\% (zwei Patienten) entwickelten nach der Neck-Dissection ein Hämatom im Halsbereich und mussten sich einer operativen Revision unterziehen. Kein Patient musste aufgrund intra- oder postoperativer Blutungen tracheotomiert werden. Ein Patient (1\%) hatte ein starkes, postoperatives Ödem des Kehlkopfes und benötigte eine Tracheotomie. Bei einem Patienten (1\%) wurde eine erhebliche obere Ösophagus-Stenose nach der kombinierten Behandlung festgestellt. In keinem Fall war es notwendig, eine sekundäre Laryngektomie aufgrund von Aspiration durchzuführen.

Tabelle 11: Anzahl und Art der Komplikationen

\begin{tabular}{lll}
\hline Komplikation & ja & nein \\
\hline Gastrostomie & 7 & 75 \\
Blutungen & 11 & 71 \\
Tracheostoma & 1 & 81 \\
Magensonde & 66 & 16 \\
Laryngektomie & 0 & 82 \\
Ösophagus-Stenose & 1 & 81 \\
\hline
\end{tabular}




\section{Diskussion}

\subsection{Bewertung der onkologischen Ergebnisse in der Literatur}

Zungengrundkarzinome können sowohl primär chirurgisch mit oder ohne adjuvanter Radio(chemo)therapie als auch primär radio-(chemo)therapeutisch behandelt werden. Die Auswahl der Therapie für Patienten ist oft abhängig von der aufgesuchten Klinik. Eine solche Entscheidungsfindung ist verbunden mit Präferenz und Erfahrungen des Arztes oder einer aktuellen Studie (Parsons et al. 2002). In den USA spielt die primäre Radiotherapie verglichen mit Deutschland eine größere Rolle, wo die operative Therapie im Vordergrund steht (Wittekindt et al. 2012). Trotz Fortschritten in der Therapie ist die Prognose nach wie vor schlecht (Zhen et al. 2004). Prinzipiell wird der Vergleich von Studien erschwert, weil in manchen Studien nur Zungengrundtumoren und in anderen Oropharynxtumoren ausgewertet worden sind. Besonders bei der Behandlung von T3- und T4-Tumoren sprechen sich viele Autoren für den Einsatz einer Kombinationstherapie mit primärer Chirurgie und adjuvanter Strahlentherapie aus (Foote et al. 1993).

\subsubsection{Gesamtüberleben nach offener Chirurgie alleine oder mit adjuvanter Radio(chemo)therapie}

Gourin und Johnson (2001) führten eine primäre chirurgische Therapie bei 87 Patienten durch, von denen sich 79 Patienten (91\%) in Stadium III oder IV befanden. 93\% der Patienten erhielten eine adjuvante Radio(chemo)therapie. Das Gesamtüberleben lag bei $49 \%$ nach fünf Jahren. Die Autoren waren mit den Ergebnissen dieser Therapie zufrieden, entschieden sich aber dafür in fortgeschrittenen Stadien aufgrund unbefriedigender funktioneller Ergebnisse eine primäre Radio(chemo)therapie anzubieten. Indikation für eine adjuvante Therapie in dieser Studie waren unter anderem positive Resektionsränder und Lymphknotenmetastasen im N3- und N2b-Stadium. Zelefsky et al. (1992) operierten Zungengrundkarzinome in den fortgeschrittenen Stadien T3 und T4 und erreichten ein Gesamtüberleben nach sieben Jahren von 52\%, wobei von den insgesamt 51 Patienten 31 Patienten ein Zungengrundkarzinom hatten und 20 Patienten ein Tonsillenkarzinom. Eine adjuvante Radiotherapie erfolgte ebenfalls bei positiven Resektionsrändern oder multiplen Lymphknotenmetastasen. Von den insgesamt 51 Patienten erhielten 17 Patienten (33\%) eine adjuvante Radiotherapie.

Rodrigo et al. (2011) untersuchten funktionelle und onkologische Ergebnisse nach 
primärer offener, transhyoidaler Chirurgie in Kombination mit adjuvanter Radiotherapie bei 64 von insgesamt 84 Patienten. Fünf Patienten befanden sich in Stadium II, sechs in Stadium III, 58 in Stadium IV A, und 15 in Stadium IV B. Das Gesamtüberleben betrug 19\% nach fünf Jahren. Die Fünf-Jahres-Gesamtüberlebensraten betrugen 40\%, 33\%, 18\% und $8 \%$ für die Stadien II bis IV B. Der transhyoidale Zugang erlaubte eine adäquate Resektion mit niedriger Morbidität in frühen Stadien bei einer kleinen Anzahl ausgewählter Patienten. Sowohl die funktionellen Ergebnisse als auch das Gesamtüberleben waren in fortgeschrittenen Stadien unbefriedigend.

Zhen et al. (2004) verfolgten in einer retrospektiven Studie 16.188 Fälle, wobei sich über die Hälfte der Patienten in Stadium III oder IV befanden. Chirurgie sowie Radio(chemo)therapie (26,9\%) gegenüber der alleinigen Radio(chemo)therapie $(24,5 \%)$ waren die häufigsten Behandlungen. In fortgeschrittenen Stadien (III und IV) erreichte die Kombinationstherapie mit Chirurgie und Strahlentherapie das beste Ergebnis in Bezug auf das Gesamtüberleben (51,1\%) und die Strahlentherapie allein das schlechteste Ergebnis (24,3\%).

Al- Qahtani et al. (2014) zeigten in ihrer Studie onkologische und funktionelle Ergebnisse nach Kombinationstherapie mit konservativer Chirurgie und postoperativer Radio(chemo)therapie bei 66 Patienten mit Zungengrundtumoren im Stadium III und IV. Für das Gesamtkollektiv lag das Gesamtüberleben nach fünf Jahren bei $52,2 \%$.

Nisi et al. (1998) verglichen die Kombinationstherapie, angewandt bei 24 Patienten, mit der Chirurgie allein bei 55 Patienten in fortgeschrittenem Stadium bezüglich onkologischer Ergebnisse.

Das Gesamtüberleben für das chirurgische Verfahren allein betrug $41 \%$. Chirurgie plus adjuvante Radiation erreichte ein Gesamtüberleben von 53\%. Die Behandlung mit adjuvanter Therapie bewirkte ihrer Meinung nach eine verbesserte lokale Kontrolle, ohne dass sich das Gesamtüberleben signifikant verbesserte. Die Göttinger Ergebnisse zeigten bessere Ergebnisse bei einem Gesamtüberleben von $70,4 \%$ in den Stadien I und II, 44\% für das Stadium III und 58\% für das Stadium IV. Das Gesamtüberleben für das gesamte Patientenkollektiv lag bei 59\%. Die Ergebnisse in der Literatur bezüglich der Gesamtüberlebensrate nach Kombinationstherapie mit offener Chirurgie nach fünf Jahren reichen von 19-53\% (Rodrigo et al. 2011, Zelefsky et al. 1992, Al- Qahtani et al. 2014, Nisi et al. 1998). Das Gesamtüberleben in der Göttinger Studie war im Vergleich etwas besser 
mit 59\% nach transoraler Laserchirurgie mit oder ohne adjuvante Radio(chemo)therapie. Die vorliegenden Daten zeigen, dass das Gesamtüberleben beim Zugengrundkarzinom insgesamt nicht zufriedenstellend ist. Über die Jahre hinweg hat sich das Gesamtüberleben nicht wesentlich verbessert.

Einige Autoren sehen den Grund darin, dass nach Kombinationstherapien die lokale Kontrolle besser wird, jedoch mehr Fernmetastasen auftreten (Kraus et al. 1993, Parsons et al. 2000, Steiner et al. 2003).

\subsubsection{Lokale Kontrolle nach Kombinationstherapie}

In der Literatur betrugen die lokalen Kontrollraten in frühen Stadien von Zungengrundkarzinomen zwischen $75 \%$ und $85 \%$ (Harrison et al. 2003) und für fortgeschrittene Stadien zwischen 77\% und 96\% für T3- und T4-Läsionen (Nisi et al. 1998, Zhen et al. 2004, Gourin und Johnson 2001). Nach Nisi et al. (1998) war die lokale Kontrolle signifikant besser nach Kombinationstherapie. Die lokalen Kontrollen für die Chirurgie-Gruppe ihrer Studie betrugen: T1: 77\%, T2: 81\% und T3: $77 \%$. Die lokalen Kontrollen für die Chirurgie und adjuvante RadiotherapieGruppe betrugen: T1: 100\%, T2: 100\% und T3: 75\%.

Lokale Rezidive bei T3- und T4-Tumoren traten nach Zhen et al. (2004) nach chirurgischer Behandlung in Kombination mit einer Radio(chemo)therapie seltener auf. So zeigten Daten der US National Cancer Database 2004 bessere Ergebnisse für die Chirurgie in Kombination mit postoperativer Strahlentherapie vor allem in fortgeschrittenen Stadien. Für das Stadium IV allein lag die lokoregionäre Kontrolle bei $50 \%$. Nach Rodrigo et al. (2011) traten lokale Rezidive in $55 \%$ in Stadium T2, in 45\% in Stadium T3 und in 58\% in Stadium T4 auf. Dieser Wert ist mit den in Göttingen erhobenen Daten vergleichbar. Die lokale Kontrolle betrug für das Gesamtkollektiv $84 \%$. Die T-Stadium-bezogene lokale Kontrolle nach fünf Jahren betrug $94 \%$ für die Stadien I bis II, $78 \%$ für das Stadium III und $81 \%$ für das Stadium IV.

Nach Betrachtung der onkologischen Ergebnisse nach Kombinationstherapie kann zusammenfassend gesagt werden, dass für resektable Tumoren eine Operation mit adjuvanter Strahlentherapie die onkologischen Ergebnisse verbessert. In Deutschland kann die Kombinationstherapie als standard of care betrachtet werden (Wittekindt et al. 2012). 


\subsubsection{Onkologische Ergebnisse nach primärer Strahlentherapie}

Kopf- und Hals-Tumoren werden im deutschen Raum bevorzugt operiert (Wittekindt et al. 2012). Prinzipiell können Zungengrundtumoren auch im Rahmen der kurativen Therapie primär radio(chemo)therapiert werden (Bootz 2000).

Dabei ist die simultane Radio(chemo)therapie eine Alternative zu der Operation, wenn diese nicht geplant oder möglich ist. Die Radiotherapie kann aber auch adjuvant oder palliativ erfolgen (Bootz 2000). Bestrahlungsarten sind die perkutane Strahlentherapie, zu der die intensitätsmodulierte Strahlentherapie (IMRT) gehört, und die Brachytherapie (Bootz et al. 2000).

In Deutschland ist eine normofraktionierte Bestrahlung von Kopf- und Hals-Tumoren der Standard. Der Tumor wird mit einer Einzeldosis von 1,8 bis 2 Gy (eine Fraktion) an fünf Tagen die Woche bestrahlt bis eine Gesamtdosis von 70 Gy erreicht wird (Fu et al. 2000). Damit wird erreicht, dass sich die Spättoxizität verringert (Höcht und Hinkelbein 2004). Bei der Hyperfraktionierung werden täglich zwei Fraktionen appliziert mit Reduzierung der einzelnen Fraktionsdosis. In der Literatur scheint die simultane Radiochemotherapie höhere Tumorkontrollraten und Überlebensvorteile zu haben im Vergleich zu der alleinigen Strahlentherapie in höheren Stadien (Bootz 2000, Pignon et al. 2009). Besonders bei fortgeschrittenen Tumoren war die Prognose mit einer alleinigen Radiotherapie mit einem Drei-Jahres-Gesamtüberleben und einer lokoregionären Kontrolle von 30\%-40\% in der Literatur schlecht (Budach et al. 2005). So bestand nach Gebhardt (2013) eine bessere lokale Kontrolle und besseres Gesamtüberleben nach kombinierter Radiochemotherapie. Sie erzielten bei 48 Patienten mit einer Radio(chemo)therapie eine lokale Kontrolle von $67 \%$. Das Gesamtüberleben betrug $48 \%$ nach fünf Jahren. Auch Budach et al. (2005) zeigten bei fortgeschrittenen Kopf- und Hals-Tumoren mit der hyperfraktionierten Radiochemotherapie (C-HART) bessere onkologische Ergebnisse als mit der alleinigen hyperfraktionierten Radiotherapie (HART).

Die C-HART hatte ein Gesamtüberleben von 28,6\% und eine lokoregionäre Kontrolle von 49,9\% nach fünf Jahren zur Folge. Im Gegensatz dazu zeigte sich bei der HART ein Gesamtüberleben von 23,7\% und eine lokoregionäre Kontrolle von $37,4 \%$ nach fünf Jahren. Durch die simultane Anwendung sind jedoch die akuten Nebenwirkungen erhöht (Bootz 2000, Budach et al. 2005).

Myers et al. 2012 erreichten nach Radio(chemo)therapie von fortgeschrittenen Oropharynxkarzinomen ein Gesamtüberleben von 72,3\% nach 3 Jahren. 


\subsubsection{Lokale Kontrolle nach Laserchirurgie mit oder ohne adjuvante Radio- (chemo)therapie}

Steiner et al. (1991) begannen vor 30 Jahren mit der transoralen Resektion von Oropharynxkarzinomen der Stadien T1 und T2 und mit zunehmender Erfahrung auch der fortgeschrittenen Stadien (T3 und T4) unter mikroskopischer Vergrößerung, in kurativer Absicht und funktionserhaltend. Diese Therapie sollte so organ- und damit funktionserhaltend wie möglich sein. Üblicherweise erfolgt neben der transoralen Laserchirurgie eine simultane oder zeitlich versetzte NeckDissection. Die lokale Kontrolle nach Henstrom et al. (2009) war 83,6\% nach drei Jahren. Therapieergebnisse nach transoraler Lasermikrochirurgie in kurativer Absicht bei Zungengrundkarzinomen wurden 2003 von Steiner et al. publiziert. Im Rahmen der Arbeit wurde der Verlauf von 48 Patienten, die zwischen 1986 und 1997 mit transoraler Lasermikrochirurgie aufgrund eines Zungengrundkarzinoms behandelt wurden, beobachtet. Die lokale Kontrolle nach fünf Jahren betrug 85\%. Es gab keine Lokalrezidive in T1- oder T2-Läsionen, jedoch $20 \%$ Lokalrezidive in T3- und T4-Tumoren. Im Stadium IVa traten nach alleiniger chirurgischen Therapie in $20 \%$ Lokalrezidive auf und nach Kombinationstherapie in 10\%. Andere Gruppen stellten auch ihre Resultate mit der transoralen Laser-Mikrochirurgie vor. Grant et al. (2009) untersuchten 69 Patienten, die mit Oropharynxkarzinomen mit der transoralen Laserchirurgie therapiert wurden, wobei 59 Patienten insgesamt zusätzlich eine Neck-Dissection erhielten. 25 Patienten wurden postoperativ bestrahlt. Sie berichteten über eine lokale Kontrolle für T1-Tumoren bei $90 \%$ und für T2-Tumoren bei $94 \%$. Kein Patient im T3- oder T4-Stadium hatte ein Lokalrezidiv. Haughey et al. (2011) stellten die Wirksamkeit der transoralen Laser-Mikrochirurgie bei 204 Patienten mit fortgeschrittenem Oropharynxkarzinom (Tonsillen und Zungengrund) dar mit guten onkologischen und funktionellen Ergebnissen. Bei 135 Patienten lag ein N2-Stadium vor. 150 Patienten erhielten bei Lymphknotenmetastasen eine adjuvante Bestrahlung. Die lokale Kontrolle nach drei Jahren lag bei $97 \%$. Chauhan et al. (2014) erreichten nach 19 Monaten eine lokale Kontrolle von $100 \%$. Unsere Ergebnisse zeigen eine lokale Kontrollrate von $83,7 \%$ nach fünf Jahren. 
Verglichen mit den Studien von Haughey et al. (2011) und Chauhan et al. (2014) ist das Göttinger Ergebnis schlechter, bei jedoch längerem Follow-up. Somit stimmen insgesamt die Ergebnisse in der Literatur mit unseren überein. Bei fast $84 \%$ des Gesamtkollektivs bei den Göttinger Ergebnissen trat nach fünf Jahren kein Lokalrezidiv auf. Bei insgesamt elf Patienten (13\%) ist nach fünf Jahren ein Lokalrezidiv aufgetreten. Insgesamt zeigen die Resultate, dass eine gute lokale Kontrollrate auch in fortgeschrittenen Stadien durch die TLM erreicht werden kann.

\subsubsection{Gesamtüberleben nach Laserchirurgie alleine oder mit adjuvanter Radio(chemo)therapie}

Die Überlebensrate des gesamten Patientenkollektivs nach transoraler Lasermikrochirurgie nach Steiner et al. (2003) belief sich nach 5 Jahren auf 52\%. Grant et al. (2009) berichteten über eine Fünf-Jahres-Überlebenszeit von $86 \%$, wobei sich zwölf Patienten im T3- und zwei Patienten im T4-Stadium befanden. Als relative Kontraindikation sah man Faktoren, die zu einem unzureichenden endoskopischen Zugang zum Tumor führten. Bei den 44 Patienten, die keine adjuvante Therapie erhielten lag die 5-Jahres Überebensrate bei $86 \%$. Bei den Patienten, bei denen eine Indikation für eine adjuvante Therapie bestand, wiesen die Patienten im Stadium IV eine Gesamtüberlebensrate von 49\% auf. Haughey et al. (2011) erreichten eine Drei-Jahres-Überlebensrate von 86\%. Chauhan et al. (2014) erreichten ein Gesamtüberleben von 82\% nach 19 Monaten. In der vorliegenden Arbeit wurde eine Fünf-Jahres-Gesamtüberlebensrate von 59\% nach Kaplan-Meier (Kaplan und Meier 1958) errechnet.

Die ermittelten Stadien-bezogenen Fünf-Jahres-Überlebenszeiten betrugen nach der TLM in kurativer Absicht $70 \%$ für die Stadien I und II, 44\% für Stadium III und $58 \%$ für Stadium IV.

Die Überlebenszeiten befinden sich damit nahe den Ergebnissen von Zhen et al. (2004) nach konservativer Therapie sowie von Steiner et al. (2013).

Die Resultate in der Literatur zeigten sogar bessere Gesamtüberlebensraten, von 82-86\% (Grant et al. 2009, Haughey et al. 2011, Chauhan et al. 2014). Hier zeigten sich jedoch teilweise kurze Follow-ups mit z.B. 19 Monate bei Chauhan et al. (2014). Die Ergebnisse dieser Studien sowie der vorliegenden Arbeit zeigen, dass mit organerhaltender Lasermikrochirurgie und anschließender adjuvanter Radio(chemo)therapie im Vergleich zur Radikalchirurgie und anschließender adjuvanter Radio(chemo)therapie bei lokal fortgeschrittenen Kopf-Hals-Tumoren 
vergleichbare onkologische Ergebnisse erzielt werden können. Da zur Zeit viele Karzinome konservativ behandelt werden oder mit offener Chirurgie, bietet die transorale Laserchirurgie eine Alternative mit ebenfalls guten onkologischen Ergebnissen.

Die folgende Tabelle 12 fasst die Daten in den Studien bezüglich der lokalen Kontrolle und des Gesamtüberlebens bei Oropharynxkarzinom und Zungengrundkarzinom zusammen.

Tabelle12: Ergebnisse der Studien (CT = Chemotherapie, RT = Radiotherapie, OP = konventionelle Operation, TLM = transorale Lasermikrochirurgie)

\begin{tabular}{|c|c|c|c|c|}
\hline Studie & Patientenzahl & $\begin{array}{l}\text { Tumor- } \\
\text { stadien }\end{array}$ & $\begin{array}{l}\text { Fünf-/Drei- } \\
\text { Jahres-/lokale } \\
\text { Kontrolle }\end{array}$ & $\begin{array}{l}\text { Fünf-/Drei- } \\
\text { Jahres-Gesamt- } \\
\text { überleben }\end{array}$ \\
\hline $\begin{array}{l}\text { Machtay et al. (1997), } \\
\text { Zungengrund }\end{array}$ & $53(\mathrm{RT}+\mathrm{CT})$ & $\begin{array}{l}\text { T1 bis T4 } \\
\text { III bis IV }\end{array}$ & 3 Jahre: $77 \%$ & 3 Jahre: $70 \%$ \\
\hline $\begin{array}{l}\text { Huang et al. (2008), } \\
\text { Oropharynx }\end{array}$ & $71(\mathrm{RT}+\mathrm{CT})$ & $\begin{array}{l}\text { T1 bis T4 } \\
\text { III und IV }\end{array}$ & 3 Jahre: 94\% & 3 Jahre: 83\% \\
\hline $\begin{array}{l}\text { Saba et al. (2009), } \\
\text { Oropharynx }\end{array}$ & $80(\mathrm{RT}+\mathrm{CT})$ & $\begin{array}{l}\text { T1 bis T4 } \\
\text { III und IV }\end{array}$ & 3 Jahre: $87,5 \%$ & 3 Jahre: $81 \%$ \\
\hline $\begin{array}{l}\text { Parsons et al. (2002), } \\
\text { Oropharynx }\end{array}$ & $\begin{array}{l}390(\mathrm{OP}+/-\mathrm{RT}) \\
806(\mathrm{RT}+/-\mathrm{ND})\end{array}$ & $\begin{array}{l}\text { T1 bis T4 } \\
\text { I bis IV }\end{array}$ & $\begin{array}{l}5 \text { Jahre: } 79 \% \\
5 \text { Jahre: } 76 \%\end{array}$ & $\begin{array}{l}5 \text { Jahre: } 49 \% \\
5 \text { Jahre: } 52 \%\end{array}$ \\
\hline $\begin{array}{l}\text { Foote et al. (1993), } \\
\text { Zungengrund }\end{array}$ & $55(\mathrm{OP})$ & $\begin{array}{l}\text { T1 bis T4 } \\
\text { I bis IV }\end{array}$ & 5 Jahre: $74 \%$ & 5 Jahre: $55 \%$ \\
\hline $\begin{array}{l}\text { Steiner et al. (2003), } \\
\text { Zungengrund }\end{array}$ & $\begin{array}{l}48 \mathrm{TLM}+/-\mathrm{RT}+/- \\
\mathrm{CT}+/-\mathrm{ND})\end{array}$ & $\begin{array}{l}\text { T1 bis T4 } \\
\text { III bis IV }\end{array}$ & 5 Jahre: 85\% & 5 Jahre: $52 \%$ \\
\hline $\begin{array}{l}\text { Grant et al. (2009), } \\
\text { Oropharynx }\end{array}$ & $59 \mathrm{OP}+\mathrm{RT}(28)$ & $\begin{array}{l}\text { T1 bis T4 } \\
\text { I bis IV }\end{array}$ & 5Jahre: 94\% & 5 Jahre: $69 \%$ \\
\hline $\begin{array}{l}\text { Haughey et al. (2011), } \\
\text { Oropharynx }\end{array}$ & 204 (TLM) & $\begin{array}{l}\text { T1 bis T4 } \\
\text { III und IV }\end{array}$ & 3 Jahre:86\% & 5 Jahre: $78 \%$ \\
\hline aktuelle Arbeit & $\begin{array}{l}82 \text { (TLM +/- RT } \\
+/- \text { CT +/- ND) }\end{array}$ & $\begin{array}{l}\text { T1 bis T4 } \\
\text { I bis IV }\end{array}$ & 5 Jahre: 84\% & 5 Jahre: 59\% \\
\hline
\end{tabular}




\subsection{Fernmetastasen nach primärer Chirurgie}

In den letzten Jahren haben Fortschritte in der Therapie Verbesserungen in den onkologischen Ergebnissen erbracht. Doch trotz dieser Fortschritte verblieb die Überlebenszeit für alle Stadien immer noch unter $50 \%$, weil eine Verschiebung von nun selteneren lokoregionären Rezidiven zu häufigeren Fernmetastasen stattfand (Steiner et al. 2003). Fernmetastasen traten in der Studie von Nisi et al. (1998) bei sieben Patienten (13\%) von 55 Patienten auf, die eine alleinige offene chirurgische Therapie erhielten und bei vier Patienten (17\%) von 24 Patienten, die eine adjuvante Radiotherapie erhielten. Das N-Stadium war nach Nisi et al. (1998) ein signifikanter Prädiktor für das Auftreten von Fernmetastasen. Bei Haughey et al. (2011) wurde ebenfalls beobachtet, dass Fernmetastasen nur bei Patienten mit befallenen Lymphknoten aufgetreten sind. In der Studie von Steiner et al. (2003) traten Fernmetastasen bei sechs von 48 Patienten (6\%) ausschließlich nach Kombinationstherapie auf. Nach alleiniger konservativen Chirurgie berichteten Gourin und Johnson (2001) von einer Rate an Fernmetastasen von 5\%. Die Entwicklung von Fernmetastasen war nach Kombinationstherapie mit 24\% deutlich höher in der Studie von Zelefsky et al. (1992), in der 51 Patienten mit einem fortgeschrittenen Zungengrundtumor mit konservativer Chirurgie und adjuvanter Strahlentherapie behandelt wurden. In der Studie befanden sich 51 Patienten, 31 davon mit einem Plattenepithelkarzinom des Zungengrundes und 20 Patienten mit einem Tonsillenkarzinom.

Kraus et al. (1993) beobachteten ebenfalls eine Zunahme an Fernmetastasen nach Kombinationstherapie mit einer Rate von $22 \%$. Sie sahen die Ursache darin, dass bei fortgeschrittenen Tumoren eine Kombinationstherapie angewandt wird, welche die lokoregionäre Kontrolle und somit das Überleben verbessert, wodurch jedoch die Anzahl an Fernmetastasen zunimmt.

In den Göttinger Daten wiesen insgesamt zwei Patienten (2\%) Fernmetastasen auf. Dies zeigt, dass die Rate an Fernmetastasen nach Lasertherapie nicht erhöht ist. 


\subsection{Bewertung der funktionellen Ergebnisse in der Literatur}

\subsubsection{Funktionelle Ergebnisse im Vergleich von konventioneller Chirurgie und primärer Radio(chemo)therapie}

Friedlander et al. (2002) untersuchten die funktionellen Ergebnisse bei 26 Patienten, die sich einer primären Operation eines Zungengrundkarzinoms unterzogen. Die meisten dieser Patienten waren in der Lage, in der Öffentlichkeit zu essen, hatten eine verständliche Sprache und einen insgesamt guten funktionellen Status. Patienten, bei denen eine totale Laryngektomie notwendig war, wurden aus der Studie ausgeschlossen.

$37 \%$ von 48 Patienten entwickelten in der Studie von Nguyen et al. (2007) nach Radiochemotherapie schwere Schluckstörungen. Fünf Patienten starben an Aspirationspneumonien, was die unabdingbaren akuten und späten Folgeschäden abhängig von der Höhe der Strahlendosis mit teilweise bemerkenswerten Mortalitätsraten verdeutlicht.

Huang et al. (2008) berichteten ebenfalls über signifikante Schluckstörungen nach einer intensitätsmodulierten Strahlentherapie (IMRT) bei Oropharynxkarzinomen in den Stadien III und IV. Eine Gastrostomie war in 35\% notwendig. Funktionelle Ergebnisse sind in frühen Stadien im Vergleich von Bestrahlung und Chirurgie ähnlich. Je höher das Stadium und desto höher die Dosis, desto mehr muss mit Spättoxizitäten nach Radiotherapie gerechnet werden, die nicht unerheblich sind. Bei ausgedehnten Resektionen von Pharynx, Tonsillen und Zungengrund können Probleme bezüglich Funktion und Ästhetik und somit Einschränkungen der Lebensqualität entstehen. Je höher das Stadium, desto mehr muss reseziert werden. Insbesondere im Oropharynx besteht eine enge anatomische Nähe zu funktionellen Strukturen, welche wichtig für das Sprechen und Schlucken sind. Während funktionelle Ergebnisse in frühen Stadien gut sind, entstehen in fortgeschrittenen Stadien durch ausgedehntere Resektionen häufig Schluck- und Sprechstörungen (Kraus et al. 1993). Die operative Therapie hat jedoch den Vorteil eines korrekten Stagings. Immer schneller und besser können intraoperativ histopathologische Untersuchungen von Schnellschnitten durchgeführt werden. Die histologische Untersuchung ist wichtig für die Entscheidung zugunsten der adjuvanten Therapien (Psychogios et al. 2012). Auch ist zu beachten, dass Rekonstruktionstechniken verbessert sind, z. B. mit der Entwicklung von myokutanen Insellappen und mikrovaskulär anastomosierten Gewebetransplantaten (Remmert 2001). 


\subsubsection{Funktionelle Ergebnisse nach transoraler Laserchirurgie}

Die Ergebnisse von Studien zeigen, dass mit organerhaltender Lasermikrochirurgie und anschließender adjuvanter Radio(chemo)therapie in frühen und späten Stadien von Zungengrundkarzinomen gute funktionelle Ergebnisse erzielt werden können (Grant et al. 2009, Haughey et al. 2011). In der Studie von Steiner et al. (2003) blieb bei $92 \%$ der Patienten eine normale Schluckfunktion und bei $88 \%$ eine verständliche Sprache erhalten. Laut Umfrageergebnissen zeigte sich eine deutliche postoperative Zufriedenheit mit normaler Ernährung und dem Sprachverständnis. Es wurden insgesamt 20 Patienten befragt. In der Studie von Camp et al. (2009) erfolgte bei 71 Patienten mit Zungengrundkarzinomen eine transorale Laserchirurgie mit und ohne adjuvanter Radiotherapie. Fast alle Patienten, die befragt wurden, erfuhren keine Veränderung der Schluckfunktion und 69,6\% behielten ihre Sprechfunktion bei. Bei der Studie von Camp et al. (2009) muss bedacht werden, dass nur Patienten berücksichtigt wurden, die in kurativer Absicht behandelt wurden und bei denen der Tumor resezierbar war. So wurden Patienten mit T1-, T2-, T3und kleinen T4-Läsionen eingeschlossen. Die Befragungen bezüglich der Funktionen und somit Lebensqualität konnten nur bei 65 Patienten durchgeführt werden, so dass die Ergebnisse nicht das gesamte Patientenkollektiv reflektieren.

Haughey et al. (2011) untersuchten in einer Studie die Resultate nach primärer Laserchirurgie bei fortgeschrittenen Oropharynxtumoren mit Neck-Dissection sowie mit oder ohne adjuvanter Therapie. Obwohl 75\% der Patienten eine adjuvante Radiotherapie erhielten, war eine angemessene orale Aufnahme bei fast $90 \%$ der Patienten erhalten geblieben. Die funktionellen Ergebnisse in der vorliegenden Studie mit den Göttinger Ergebnissen waren ebenfalls gut bei nur 5 Patienten insgesamt, die aufgrund persistierender Schluckstörungen eine dauerhafte Gastrostomie benötigten. Die Resultate zeigen, dass die Laserchirurgie eine angemessene Therapie bei den Oropharynxkarzinomen ist und zu Recht in der kurativen und palliativen Therapie dieser eingesetzt wird. Eine häufigere Anwendung ist in Betracht zu ziehen. Als klare Indikation gelten T1- und T2Tumoren. Das primäre Ziel dieser Therapie ist die onkologisch sichere Resektion, die maximale Erhaltung der natürlichen Funktionen sowie die Verbesserung der Lebensqualität. Zusammenfassend kann gesagt werden, dass die transorale Laserchirurgie bei ausgewählten Tumoren, die endoskopisch zugänglich sind, gute funktionelle Ergebnisse hervorbringt, weshalb zu überlegen ist, diese Methode häufiger anzuwenden. Erstrebenswert sind weitere prospektive Studien mit 
standardisierten Operationsverfahren, um diese Aussage zu untermauern. Die Studie von Haughey et al. (2011) zeigte, dass die Laserchirurgie auch in fortgeschrittenen Stadien von Vorteil sein kann, da die Patienten in den meisten Fällen ihre normalen Funktionen behalten, was nach konventioneller Chirurgie oft nicht der Fall ist. Der größte Nachteil der kombinierten Radiochemotherapie ist die hohe Inzindenz von frühen und späten Toxizitäten trotz verbesserten onkologischen Resultaten (Chauhan et al. 2014) als nach Radiotherapie allein (Pignon et al. 2009). Aufgrund dieser Toxizität werden prophylaktisch PEG-Sonden eingesetzt, wobei jedoch nach Chauhan et al. (2014) in der Literatur ein Drittel der Patienten diese noch nach drei Jahren besitzen. Die transorale Lasermikrochirurgie bietet eine Therapiealternative mit guten onkologischen Ergebnisse, jedoch mit reduzierter Toxizität.

\subsection{Bewertung der Komplikationen in der Literatur}

Normales Schlucken erfordert eine koordinierte Bewegung von laryngealer, pharyngealer und ösophagealer Muskulatur (Reiter und Brosch 2012). Durch die Resektion ausgedehnter Karzinome werden diese Abläufe schwerwiegend gestört. Resultat ist häufig eine ausgeprägte chronische Aspiration mit vitaler Bedrohung. So wie bei der offenen Chirurgie werden in frühen Stadien exzellente funktionelle Ergebnisse mit dem Laser erzielt, die sich aber mit zunehmender Größe des Tumors auch für den Laser verschlechtern (Steiner et al. 2003).

Nicht nur der Erhalt tumorfreier Strukturen ist ein deutlicher Vorteil der TLM gegenüber der radikalen Operation, auch eine geringere Inzidenz postoperativer Komplikationen nach Lasermikrochirurgie im Vergleich zur klassischen, offenen Operation ist beschrieben worden (Steiner et al. 2003). Das gilt z. B. für das Auftreten postoperativer Schluckstörungen mit Aspiration, welche am häufigsten nach ausgedehnter Operation auftraten und als schwere postoperative Komplikation gilt. Diese ist bei der TLM im Vergleich zu herkömmlichen offenen Operationen deutlich seltener zu beobachten (Steiner et al. 2003). So waren die häufigsten Komplikationen bei Chung et al. (2014) Wundinfektionen und Blutungen bei einem Kollektiv von 1426 Patienten, die eine herkömmliche konventionelle Chirurgie erhielten. Des Weiteren berichteten Gourin und Johnson (2001) in einer anderen Studie von über 17 totalen Laryngektomien in Folge eines Aspirationsrisikos nach offener Chirurgie und 4,6\% Fisteln. Demgegenüber zeigte ein Patientenkollektiv 
von 48 Patienten, welches sich einer transoralen Lasermikrochirurgie unterzogen hatte, in der Nachbeobachtung durch Steiner et al. (2003) nur drei Patienten (6\%) mit schweren postoperativen Aspirationen mit Anlage von Gastrostomien. Pneumonien oder Fisteln traten nicht auf. Die Rate der Schluckfunktionseinbußen erhöhte sich mit der Anwendung einer adjuvanten Behandlung. Kein Patient, der nur operativ behandelt wurde, litt unter persistierenden funktionellen Problemen. In der vorliegenden Studie mit einem Kollektiv von 82 Patienten, die eine TLM erhielten, war ebenfalls keine Fistel als Komplikation aufgetreten. Keiner der Patienten unterzog sich aus funktionellen Gründen einer sekundären Laryngektomie. Bei sieben Patienten (9\%) musste eine perkutane endoskopische Gastrostomie angelegt werden. Bei fünf Patienten (6\%) musste diese dauerhaft (bis zum Ende des Follow-up oder Tod) aufgrund persistierender Schluckstörungen und Aspirationen verbleiben. Außerdem resultierte aus der Behandlung durch TLM kein aspirationsbedingter registrierter Todesfall.

Weitere Probleme nach chirurgischen Eingriffen waren postoperative Ödembildungen in den oberen Atemwegen und damit in einigen Fällen die Notwendigkeit von Tracheotomien (Kraus et al. 1993, Foote et al. 1993). Dies waren eher seltene Komplikationen nach TLM (Bernal-Sprekelsen et al. 2004, Ambrosch und Steiner 1995).

In Göttingen wurden zwischen August 1986 und Dezember 1994704 Patienten an einem Oropharynx-, Larynx-, Mundhöhlen- und Hypopharynxkarzinom aller T-Kategorien kurativ behandelt. Es wurde untersucht, welche Komplikationen nach einer laserchirurgischen Therapie vorkommen. Nach der Resektion von Oropharynxkarzinomen traten in 6,4\% der Fälle Nachblutungen aus dem Resektionsbereich auf (Ambrosch und Steiner 1995).

In der Studie von Steiner et al. (2003) traten nach laserchirurgischen Resektionen in $10 \%$ der Fälle Nachblutungen auf. Als Ursache wurde die offene Wunde im Primärtumorbereich gesehen, welche stark durchblutet wird.

Haughey et al. (2011) berichteten über postoperative Nachblutungen bei sechs von 202 Patienten. Eine tödliche Nachblutung trat insgesamt jedoch nicht auf. Kein Patient benötigte aufgrund einer postoperativen Blutung eine Tracheotomie. In den vorliegenden ausgewerteten Daten meiner Arbeit betrug die Rate an postoperativen Nachblutungen nach transoraler Zungengrundteilresektionen 13\% (elf Patienten). Bei neun Patienten (11\%) trat die Nachblutung am Zungengrund auf und bei den 
restlichen zwei Patienten gab es Nachblutungen im Halsbereich. Aus dieser Komplikation ergab sich kein Todesfall. Die Nachblutungen erforderten am Operationstag eine Blutstillung in Narkose. Diese erfolgte unter dem Pharyngoskop mittels Koagulation und/oder Clipping. Der Vorteil der TLM gegenüber der radikalen offenen Operation war der minimale Blutverlust während des Eingriffs und danach, da der regionale Blutfluss nur geringfügig betroffen war (Steiner et al. 2001), wodurch eine bessere Sicht auf das Operationsfeld und somit eine sichere Resektion des Tumors mit Erhalt von gesundem Gewebe ermöglicht war.

Nicht nur der Funktionserhalt war ein deutlicher Vorteil der TLM im Vergleich zur konventionellen offenen Operation, sondern auch eine geringere Inzidenz postoperativer Komplikationen nach transoraler Laserchirurgie. In der Regel erfolgte keine Tracheotomie, da postoperative Ödeme selbst bei ausgedehnten Resektionen seltener entstanden.

Weitere Vorteile waren geringere postoperative Schluckbeschwerden und geringerer Blutverlust (Steiner et al. 2003).

Die Operationszeit und der postoperative Krankenhausaufenthalt waren erheblich verkürzt. Allgemeine medizinische und chirurgische Komorbidität wurden reduziert und jede notwendige adjuvante chirurgische, radio- oder chemotherapeutische Behandlung konnte ohne Nachteile für den Patienten angewendet werden. Trotz des Schneidens durch den Tumor gab es keine Häufung von Fernmetastasen. Die direkte intraoperative Koagulation von Blutgefäßen, begleitet von der herkömmlichen Koagulation größerer Gefäße, ermöglichte eine blutungsarme Präparation und somit intraoperativ eine bessere Sicht auf das Operationsfeld. Dadurch war eine genauere und sichere Resektion möglich. 


\section{Zusammenfassung}

In der vorliegenden Arbeit wird über 82 Patienten berichtet, die aufgrund eines Zungengrundkarzinoms aller T-Kategorien transoral mit einem CO2-Laser in kurativer Absicht operiert wurden. Dies geschah in einem Zeitraum zwischen 1986 und 2011. Die Fünf-Jahres-Überlebenszeit und das rezidivfreie Überleben nach Kaplan-Meier (Kaplan und Meier 1958) betrugen 59\% bzw. 69\%. Bei 11 Patienten $(13 \%)$ trat ein Rezidiv auf. Die Ergebnisse zeigen, dass die transorale Lasermikrochirurgie mit adjuvanter Radio(chemo)therapie eine effiziente Therapieoption kleiner und lokal fortgeschrittener Zungengrundkarzinome ist, ohne Funktionsminderung bei gleichzeitig günstigen onkologischen Ergebnissen. Die Komplikationsraten sind im Vergleich zur konventionellen Chirurgie geringer. Die Behandlung von Patienten mit fortgeschrittenen Zungengrundkarzinomen sollte von einem interdisziplinären Team durchgeführt werden, um eine individuell maximal mögliche Tumorbekämpfung zu erreichen. 


\section{Literaturliste}

Al-Qahtani K, Rieger J, Harris JR, Mlynarek A, Willims D, Islm T, Seikaly H (2014): Treatment of base of tongue cancer, stage III and stage IV with primary surgery: survival and functional outcomes. Eur Arch Otorhinolaryngol Epub 2014 Jun 25

Ambrosch P (2003): Laserchirurgie im oberen Aerodigestivtrakt bei bösartigen Erkrankungen. Laryngo-Rhino-Otol $\underline{82}, 114-143$

Ambrosch P, Steiner W (1995): Komplikationen nach transoraler Lasermikrochirugie von Mundhöhlen-, Rachen- und Kehlkopfkarzinomen. Otorhinolaryngol Nova $\underline{5}, 268-274$

Ambrosch P, Brinck U, Fischer G, Steiner W (1994): Spezielle Aspekte der histopathologischen Diagnostik bei der Lasermikrochirurgie von Karzinomen des oberen Aerodigestivtraktes. Laryngo-Rhino-Otol $\underline{73}, 78-83$

Ambrosch P, Rödel R, Kron, Steiner W (2001): Die transorale Lasermikrochirurgie des Larynkarzinoms - Eine retrospektive Analyse von 657 Patientenverläufen. Onkologe $\underline{7}, 505-512$

Appold S, Dörr W, Folprecht G, Grötz KA, Reiß G, Reiß M, Riesenbeck D, Waldfahrer F: Onkologische Therapie. In: Reiß M (Hrsg): Facharztwissen HNOHeilkunde: Differenzierte Diagnostik und Therapie. 1. Auflage; Springer Medizin Verlag, Heidelberg 2009, 795-905

Bernal-Sprekelsen M, Vilaseca-Gonzales I, Blanch-Alejandro JL (2004): Predictive values for aspiration after endoscopic laser resections of malignant tumors of the hypopharnx and larynx. Head Neck 26, 103-110

Bootz F (2000): Leitlinien der Deutschen Gesellschaft für Hals-Nasen-OhrenHeilkunde, Kopf- und Hals-Chirurgie Onkologie des Kopf-Hals-Bereiches. HNO $\underline{48}, 104-118$ 
Budach V, Stuschke M, Budach W, Baumann M, Geismar D, Grabenbauer G, Lammert I, Jahne K, Stueben G, Herrmann T (2005): Hyperfractionated accelerated chemoradiation with concurrent fluorouracil-mitomycin is more effective than dose-escalated hyperfractionated accelerated radiation therapy alone in locally advanced head and neck cancer: final results of the Radiotherapy Cooperative Clinical Trials Group of the German Cancer Society 95-06 Prospective Randomized Trial. J Clin Oncol 23, 1125-1135

Camp AA, Fundakowski C, Petruzzelli Gj, Emami B (2009): Functional and oncologic results following transoral laser microsurgical excision of base of tongue carcinoma. Otolaryngol Head Neck Surg 141, 66-69

Canis M, Plüquett S, Ihler F, Matthias C, Kron M, Steiner W (2012): Impact of elective neck dissection vs observation on regional recurrence and survival in cN0-staged patients with squamous cell carcinomas of the upper aerodigestive tract. Arch Otolaryngol Head Neck Surg $\underline{138}, 650-655$

Cano ER, Lai SY, Caylakli F, Johnson JT, Ferris RL, Carrau RL, Snyderman CH, Gooding WE, Simenthal AA, Myers EN (2009): Management of squamous cell carcinoma of the base of tongue with chemoradiation and brachytherapy. Head Neck $\underline{31}, 1431-1438$

Chaturvedi AK, Engels EA, Pfeiffer RM, Hernandez BY, Xiao W, Kim E, Jiang B, Goodman MT, Siburg-Saber M, Cozen W (2011): Human papillomavirus and rising oropharyngeal cancer incidence in the United States. J Clin Oncol $\underline{29}$, 4294-4301

Chauhan P, Byrne H, Taylor E, Sheahan P (2014): Oncological and functional outcomes of transoral surgery for the treatment of oropharyngeal cancer. Ir $\mathrm{J}$ Med Sci 2014 Aug 23.

Chung TK, Rosenthal EL, Magnuson JS, Carroll WR (2014): Transoral robotic surgery for oropharyngeal and tongue cancer in the United States. Lary $\underline{33}, 140$ 145

Croce A, Moretti A, Laus M, Crescenzi D (2012): Leiomyosarcoma of the base of the tongue and free edge of the epiglottis: a case report. J Med Case Rep $\underline{6}$, 1-6 
D'Souza G, Kreimer AR, Viscidi R, Pawlita M, Fakhry C, Koch WM, Westra WH, Gillison ML (2007): Case-control study of human papillomavirus and oropharyngeal cancer. N Engl J Med 356, 1944-1956

Dietz A, Rudat V, Dreyhaupt J, Pritsch M, Hoppe F, Hagen R, Pfreundner L, Schröder U, Eckel H, Hess M (2009): Induction chemotherapy with paclitaxel and cisplatin followed by radiotherapy for larynx organ preservation in advanced laryngeal and hypopharyngeal cancers offers moderate late toxicity outcome (Delos-I-trial). Eur Arch Otorhinolaryngol 266, 1291-1300

Duvvuri U, Myers JN (2009): Contemporary management of oropharyngeal cancer. Curr Probl Surg 느, 119-184

Eckel HE, Volling P, Pototschnig C, Zorowka P, Thumfart W (1995): Transoral laser resection with staged discontinuous neck dissection for oral cavity and oropharynx squamous cell carcinoma. Laryngoscope $\underline{105}$, 53-60

Foote RL, Olsen KD, Davis DL, Buskirk SJ, Stanley RJ, Kunselmann SJ, Schid DJ, DeSanto LW (1993): Base of tongue carcinoma: patterns of failure and predictors of recurrence after surgery alone. Head Neck 15, 300-307

Friedlander P, Caruana S, Singh B, Shaha A, Kraus D, Harrison L, McKiernan J, Solan J, Polyak T, Shah JP (2002): Functional status after primary surgical therapy for squamous cell carcinoma of the base of the tongue. Head Neck $\underline{24}$, 111-114

Fu KK, Pajak TF, Trotti A, Jones CU, Spencer SA, Phillips TL, Garden AS, Ridge JA, Cooper JS, Kian Ang K (2000): A RadiotherapyOncology Group (RTOG) phase III randomized study to compare hyperfractionation and two variants of accelerated fractionation radiotherapy for head and neck squamous cell carcinomas: first report of RTOG 9003. Int J Radiat Oncol Biol Phys $\underline{48}, 7-16$

Gebhardt BJ, Mendenhall CM, Morris CG, Kirwan J, McAfee WJ, Mendenhall WM (2013): Radiotherapy Alone or Combined With Chemotherapy for the Treatment of Squamous Cell Carcinoma of the Base of the Tongue. Am J Clin Oncol $\underline{00}, 1-4$ 
Gillison ML, Koch WM, Capone RB, Spafford M, Westra WH, Wu L, Zahurak ML, Daniel RW, Viglione M, Symer DE (2000): Evidence for a causal association between human papillomavirus and a subset of head and neck cancers. J Natl Cancer Inst $\underline{\text { 92, 709-720 }}$

Goon P, Stanley MA, Ebmeyer J, Steinsträsser L, Upile T, Jerjes W, BernalSprekelsen M, Görner M, Sudhoff HH (2009): HPV and head and neck cancer: a descriptive update. Head Neck Oncol $\underline{36}, 1-36$

Gourin CG, Johnson JT (2001): Surgical treatment of squamous cell carcinoma of the base of tongue. Head Neck $\underline{23}, 653-660$

Grant DG, Hinni ML, Salassa JR, Perry WC, Hayden RE, Casler JD (2009): Oropharyngeal cancer: a case for single modality treatment with transoral laser microsurgery. Arch Otolaryngol Head Neck Surg $\underline{135}, 1225-1230$

Guntinas-Lichius O: Lippen, Mundhöhle und Pharynx. In: Reiß M (Hrsg.): Facharztwissen HNO-Heilkunde: Differenzierte Diagnostik und Therapie. 1. Auflage; Springer Medizin Verlag, Heidelberg 2009, Seite 512

Haddad R, O'Neill A, Rabinowits G, Tishler R, Khuri F, Adkins D, Clark J, Sarlis N, Lorch J, Beitler JJ (2013): Induction chemotherapy followed by concurrent chemoradiotherapy (sequential chemoradiotherapy) versus concurrent chemoradiotherapy alone in locally advanced head and neck cancer (PARADIGM): a randomised phase 3 trial. Lancet Oncol 14, 257-264

Harrison LB, Ferlito A, Shaha AR, Bradley PJ, Genden EM, Rinaldo A (2003): Current philosophy on the management of cancer of the base of the tongue. Oral Oncol $\underline{39}, 101-105$

Haughey BH, Hinni ML, Salassa JR, Hayden RE, Grant DG, Rich JT, Milov S, Lewis JS, Krishna M (2011): Transoral laser microsurgery as primary treatment for advanced-stage oropharyngeal cancer: A united states multicenter study. Head Neck 33, 1683-1694

Henstrom DK, Moore EJ, Olsen KD, Kasperbauer JL, McGree M (2009): Transoral resection for squamous cell carcinoma of the base of the tongue. Arch Otolaryngol Head Neck Surg $\underline{135}, 1231-1238$ 
Höcht S, Hinkelbein W: Klinik der Strahlentherapie im Kopf-Hals-Bereich. In: Kielbassa AM (Hrsg.): Strahlentherapie im Kopf-Hals-Bereich. Implikationen für Zahnärzte, HNO-Ärzte und Radiotherapeuten, Schlütersche Verlagsgesellschaft, Hannover 2004, 35-46

Huang K, Xia P, Chuang C, Weinberg V, Glastonbury CM, Eisele DW, Lee NY, Yom SS, Phillips TL, Quivery JM (2008): Intensity-modulated chemoradiation for treatment of stage III and IV oropharyngeal carcinoma: the University of California-San Francisco experience. Cancer 113, 497-507

Iro H, Waldfahrer F: Ultraschalldiagnostik. In: Reiß M (Hrsg): Facharztwissen HNO-Heilkunde: Differenzierte Diagnostik und Therapie. 1. Auflage; Springer Medizin Verlag, Heidelberg 2009, 12-19

Kalogeridi MA, Kouloulias V, Zygogianni A, Kyrgias G (2014): Short-course hypofractionated radiochemotherapy for unresectable locally advanced cancer of the base of tongue: palliation only? A case report and short review of the literature. J Radiat Oncol $\underline{32}, 99-102$

Kaplan EL, Meier P (1958): Nonparametric Estimation from incomplete observations, J Am Statist Assn $\underline{53}, 457-481$

Kotwall C, Sako K, Razack MS, Rao U, Bakamjian V, Shedd DP (1987): Metastatic Patterns in Squamous Cell Cancer of the Head and Neck. Am J Surg $\underline{154}, 439-442$

Kraus DH, Vastola AP, Huvos AG, Spiro RH (1993): Surgical Management of squamous cell carcinoma of the base of the tongue. Am J Surg $\underline{166}, 384-388$

Kremer B, Schlöndorff G (2001): Late letal secondary hemorrhage after laser supraglottic laryngectomy. Arch Otolaryngol Head Neck Surg 127, 203-5

Kutter J, Lang F, Monnier P, Pasche P (2007): Transoral Laser Surgery for Pharyngeal and Pharyngolaryngeal Carcinomas. Arch Otolaryngol Head Neck Surg $\underline{133}, 139-44$

Lajer CB, Buchwald C (2010): The role of human papillomavirus in head and neck cancer. APMIS $\underline{118}$, 510-519 
Lassen P, Eriksen JG, Hamilton-Dutoit S, Tramm T, Alsner J, Overgaard J (2009): Effect of HPV-associated p16INK4A expression on response to radiotherapy and survival in squamous call carcinoma of the head and neck. $J$ Clin Oncol 27, 1992-1998.

Lohia S, Rajapurkar M, Nguyen SA, Sharma AK, Gillesoie MB, Day TA (2014): A Comparison of Outcomes Using Intensity-Modulated Radiation Therapy and 3Dimensional Conformal Radiation Therapy in Treatment of Oropharyngeal Cancer. JAMA Otolaryngol Head Neck Surg 140, 331-337

López-Álvarez F, Rodrigo JP, Llorente-Pendás JL, Suárez-Nieto C (2011): Transoral laser microsurgery in advanced carcinomas of larynx and pharynx. Acta Otorrinolaringol $\underline{62}, 95-102$

Machtay M, Perch S, Markiewicz D, Thaler E, CHalian A, Goldberg A, Kligerman M, Weinstein $G$ (1997): Combined surgery and postoperative radiotherapy for carcinoma of the base of tongue: analysis of treatment out-come and prognostic value of margin status. Head Neck $\underline{19}$, 494-499

Myers C, Kerr P, Cooke A, Bammeke F, Butler J, Lambert P (2012): Functional Outcomes after Treatment of Advanced Oropharyngeal Carcinoma with Radiation or Chemoradiation. J Otolaryngol Head Neck Surg 41, 108-118

Nguyen NP, Vos P, Smith HJ, Nguyen PD, Alfieri A, Karlsson U, Dutta S, Lemanski C, Nguyen ML, Sallah S (2007): Concurrent chemoradiation for locally advanced oropharyngeal cancer. Am J Otolaryngol 료, 3-8

Niederhagen B, Leipner N, Bergé S, von Lindern J-J, Appel T (2013): Stellenwert von Computertomographie und Magnetresonanztomographie bei der Diagnostik von Malignomen der Mundhöhle und des Oropharynx. MKG $\underline{4}$, 217-221 
Nisi KW, Foote RL, Bonner JA, McCaffrey TV (1998): Adjuvant radiotherapy for squamous cell carcinoma of the tongue base: improved local-regional disease control compared with surgery alone. Int J Radiat Oncol Biol Phys $\underline{41}$, 371-377

Odell MJ, Walz BJ, Reimers HJ, Varvares MA: Carcinoma of the oropharynx. In: Genden EM, Varvares MA, eds. Head and Neck Cancer: An Evidence-Based Team Approach. Thieme, Stuttgart, 2008, 24-43

Parsons JT, Mendenhall WM, Stringer SP, Amdur RJ, Hinermann RW, Villaret DB, Moore-Higgs GJ, Greene BD, Speere TW, Cassisi NJ (2002): Squamous cell carcinoma of the oropharynx: surgery, radiation therapy, or both. Cancer $\underline{94}$, 2967-2980

Patel SH, Munson ND, Grant DG, Buskirk SJ, Hinni ML, Perry WC, Foote RL, McNeil RB, Halyard MY (2014): Relapse patterns after transoral laser microsurgery and postoperative irradiation for squamous cell carcinomas of the tonsil and tongue base. Ann Otol Rhinol Laryngol $\underline{123}$, 32-39

Pederson AW, Haraf DJ, Witt ME, Stenson KM, Vokes EE, Blair EA, Salama JK (2010): Chemoradiotherapy for locoregionally advanced squamous cell carcinoma of the base of tongue. Head Neck 32, 1519-1527

Pierre CS, Dassonville O, Chamorey E (2014): Long-term functional outcomes and quality of life after oncologic surgery and microvascular reconstruction in patients with oral or oropharyngeal cancer. Acta Otolaryngol 134, 1086-93

Pignon JP, le Maître A, Maillard E, Bourhis J (2009): Meta-analysis of cheomtherapy in head and neck cancer (MACH-NC): an update on 93 randomised trials and 17,346 patients. Radiother Oncol $\underline{92}, 4-14$

Psychogios G, Mantsopoulos K, Kuenzel J, Koch M, Zenk J, Harreus U, Waldfahrer F, Iro H (2012): Primary surgical treatment of T2 oropharyngeal carcinoma. J Surg Oncol 105, 719-723

Quon H, O'Malley BW, Weinstein GS (2010): Transoral robotic surgery (TORS) for head and neck: current and future indications. Intl J Head Neck Surg 1, 133140 
Reiter R, Brosch S (2012): Oropharyngeale Dysphagien - ein Update Teil 1: Physiologie, Pathologie und Diagnostik Update Oropharyngeal Dysphagia Part 1: Physiology, Pathology and Diagnosis. Laryngo-Rhino-Otol $\underline{91}$, 224-227

Remmert S (2001): Rekonstruktion von großen Defekten der Zunge. HNO $\underline{49}$, 143-157

Rodrigo JP, Diaz-Molina JP, Moreno C, Suaréz C (2011): Oncologic and functional results after transhyoid surgical approach for cancer of the base of tongue. Head Neck $\underline{33}, 1079-1084$

Saba NF, Edelman S, Tighiouart M, Gaultney J, Davis LW, Khuri FR, Chen A, Grist W, Shin DM (2009): Concurrent chemotherapy with intensity-modulated radiation therapy for locally advanced squamous cell carcinoma of the larynx and oropharynx: a retrospective single-institution analysis. Head Neck $\underline{31}, 1447-$ 1455

Sigal R, Zagdanski AM, Schwaab, G Bosq J, Auperin A, Laplanche A, Francke JP, Eschwège F, Luboinski $B$, Vanel D (1996): CT and MR imaging of squamous cell carcinoma of the tongue and floor of the mouth. Radiographics $\underline{16}, 787-810$

Sobin LH, C.C. Compton (2010) TNM seventh edition: what's new, what's changed: communication from the International Union Against Cancer and the American Joint Committee on Cancer. Cancer 116, 5336-5339

Steiner W, Aurbach G, Ambrosch P (1991): Minimally invasive therapy in otorhinolaryngology and head and neck surgery. Minimally Invasive Therapy 1 , $57-70$

Steiner W, Fierek O, Ambrosch A (2003): Transoral laser microsurgery for squamous cell carcinoma of the base of the tongue. Archives: Otolaryngol Head Neck Surg 129, 36-43

Steiner W, Ambrosch P, Hess CF, Kron M (2001): Organ preservation by transoral laser microsurgery in piriform sinus carcinoma. Otolaryngol Head Neck Surg $\underline{124}, 58-67$

Strnad V, Lotter M, Kreppner S Fietkau R (2013): Interstitial pulsed-dose-rate brachytherapy for head and neck cancer--Single-institution long-term results of 385 patients. Brachy 12, 521-527 
Sturgis EM, Cinciripini PM (2007): Trends in head and neck cancer incidence in relation to smoking prevalence: an emerging epidemic of human papillomavirusassociated cancers? Cancer $\underline{110}, 1429-1435$

Weber A, Schmid K W, Tannapfel A, Wittekindt C (2010): Changes in the TNM classification of head and neck tumors. Pathologe $\underline{31}, 339-343$

Werner JA, Lippert BM, Schünke M, Rudert H (1995): Tierexperimentelle Untersuchungen zur Laserwirkung auf Lymphgefaße. Laryngorhinootol $\underline{74}$, 748755

Werner JA, Dünne AA, Folz BJ, Lippert BM (2002): Transoral laser microsurgery in carcinomas of the oral cavity, pharynx and larynx. Cancer Control $\underline{9}, 379-386$

Wittekindt C, Wagner S, Mayer CS, Klußmann JP (2012): Grundlagen der Tumorentstehung und und die Bedeutung Humaner Papillomaviren (HPV) bei Kopf-Hals-Karzinomen. Laryngorhinootol $\underline{91}$, 1-26

Zbären P, Becker M, Lang H (1996): Pretherapeuthic staging of laryngeal carcinoma. Clinical findings, computed tomography, ad magnetic resonance imaging compared histopathology. Cancer $\underline{77}, 1263-1273$

Zeitels SM, Burns JA (2006): Laser applications in laryngology: past, present, and future. Otolaryngol Clin North Am $\underline{39}$, 159-172

Zelefsky MJ, Harrison LB, Armstrong JG (1992): Long-term treatment results of post-operative radiation therapy for advanced stage oropharyngeal carcinoma. Cancer $\underline{70}$, 2388-2395

Zhen W, Karnell LH, Hoffman HT, Funk GF, Buatti JM, Menck HR (2004): The National Cancer Data Base report on squamous cell carcinoma of the base of tongue. Head Neck $\underline{26}$, 660-674 


\section{Abkürzungsverzeichnis}

60CO: Cobalt-60

cGy: centigray

DNA: Desoxyribonukleinsäure

EBV: Epstein-Barr-Virus

Gy: Gray

HIV: Humane Immundefizienz-Virus

$\mathrm{MeV}$ : (Megaelektronenvolt)

MV: Megavolt

R0: Resektionsrand mikroskopisch tumorfrei

R1: Resektionsrand makroskopisch tumorfrei

R2: Resektionsrand mit makroskopisch verliebenen Tumorresten 


\section{Danksagung}

Ich möchte allen danken, die zum Gelingen dieser Arbeit beigetragen haben, vor allem Prof. Dr. Canis für die Überlassung des Themas und die wertvolle Unterstützung bei der Anfertigung dieser Arbeit. 


\section{Lebenslauf}

Ich wurde am 27.12.1984 als erste Tochter von Akram Iskandar und Houda Ali in Bad Berleburg geboren. Von 1991 bis 1995 besuchte ich die Driebe-Grundschule in Königslutter, 1995 bis 1997 die Orientierungsstufe Wilhelmbode in Königslutter. Von 1997 bis 2004 besuchte ich das Anna-Sophianeum-Gymnasium in Schöningen. Nach meiner im Jahre 2004 erlangten Hochschulreife, leistete ich von 2004 bis 2005 ein freiwilliges soziales Jahr in Helmstedt-Wolfenbüttel in einem Sprachheilkindergarten ab. Im Wintersemester 2005 begann ich das Medizinstudium an der Universität Göttingen, wobei ich 2007 das Physikum und 2011 das Staatsexamen ablegte. Mein praktisches Jahr absolvierte ich in den USA und in Göttingen. Im März 2012 begann ich nach dem Bestehen des Staatsexamens in der Abteilung für Innere Medizin des Evangelischen Krankenhauses in Ludwigsfelde zu arbeiten. Seit August 2012 arbeite ich in der psychiatrischen Abteilung des Vivantes-Klinikum in Berlin-Spandau. 